\title{
Cooperation between research companies and manufacturing firms: the choice between market contract, vertical merger, and an R+D-alliance
}

Citation for published version (APA):

van Wegberg, M. J. (1995). Cooperation between research companies and manufacturing firms: the choice between market contract, vertical merger, and an $R+D$-alliance. METEOR, Maastricht University School of Business and Economics. METEOR Research Memorandum No. 006 https://doi.org/10.26481/umamet.1995006

Document status and date:

Published: 01/01/1995

DOI:

10.26481/umamet.1995006

Document Version:

Publisher's PDF, also known as Version of record

Please check the document version of this publication:

- A submitted manuscript is the version of the article upon submission and before peer-review. There can be important differences between the submitted version and the official published version of record.

People interested in the research are advised to contact the author for the final version of the publication, or visit the DOI to the publisher's website.

- The final author version and the galley proof are versions of the publication after peer review.

- The final published version features the final layout of the paper including the volume, issue and page numbers.

Link to publication

\footnotetext{
General rights rights.

- You may freely distribute the URL identifying the publication in the public portal. please follow below link for the End User Agreement:

www.umlib.nl/taverne-license

Take down policy

If you believe that this document breaches copyright please contact us at:

repository@maastrichtuniversity.nl

providing details and we will investigate your claim.
}

Copyright and moral rights for the publications made accessible in the public portal are retained by the authors and/or other copyright owners and it is a condition of accessing publications that users recognise and abide by the legal requirements associated with these

- Users may download and print one copy of any publication from the public portal for the purpose of private study or research.

- You may not further distribute the material or use it for any profit-making activity or commercial gain

If the publication is distributed under the terms of Article 25fa of the Dutch Copyright Act, indicated by the "Taverne" license above, 
Cooperation between Research Companies and Manufacturing Firms:

The Choice between Market Contract, Vertical Merger, and an R\&D-Alliance

by

Marc van Wegberg ${ }^{1}$

In the information technology industries there are several instances of a division of labour between research companies and manufacturers, who apply the researcher's know how in production. Fims use several different ways to organise the decision making and transfer of know how. The paper compares a market transaction, where know how is sold for a license fee, to two modes of cooperation: a merger and an R\&D alliance.

JEL Code (new series): L22; L82

1. Faculty of Economics and Business Administration, Rijksuniversiteit Limburg, P.O. Box 616, 6200 MD Maastricht, The Netherlands. Tel. +31 43 883654. Fax: +31 43 258495. E-mail M.vanWegberg@MW.RuLimburg.nl. I thank the Netherlands Science Foundation, NWO, for a grant that supported the research. 


\section{Introduction}

New developments in information technology (IT) give rise to a spate of alliances and mergers. It is clear to observers that these are related to technological developments. For example, the emergence of interactive television has inspired numerous alliances, e.g., Business Week (7-6-93, p. 56-7) mentions six of them. Interactive television also provided a rationale for the acquisition battle around Paramount, which Viacom eventually won in 1994 for $\$ 10$ billion. Mergers and alliances may combine rivals (by a horizontal merger or alliance) or supplier and buyers (in a vertical merger or alliance).

A special, and interesting, case of a vertical merger or alliance occurs when research companies cooperate with manufacturing firms. The former supply an input (know how) to the latter. In many examples, an upstart firm develops a new technology that large firms subsequently take into production and commercialise. The upstart company EO Corp developed a personal digital assistant cum telephone, and depended on AT\&T for additional resources. To this end, AT\&T acquired EO Corp. The upstart firm 3DO designed an operating system for multimedia machines. It licenses the operating system to manufacturers of the machines, such as Panasonic, and to suppliers of software, such as Electronic Arts (for 3 dollar per unit of software sold, hence the name). Several large companies that cooperate with 3DO have acquired a stake in it, such as Time Warner, Matsushita, AT\&T, and Electronic Arts. The innovator can also be an established firm, whose innovation applies to a new market. For example, Apple developed a personal digital assistant, the Newton, and relies on Sharp for manufacturing the machine, that competes with Sharp's version of the Newton in the market place. There is cooperation and competition, therefore.

These examples raise the question: how should a downstream firm (that manufactures hardware or software) relate to the (upstream) researchers who provide know how? They may relate by means of contracts in the market for know how. That is, each manufacturer buys the best technology available, at any moment in time. In the setting of 3DO, for example, nothing prevents manufacturers from switching from its operating system to someone else's. They have no commitment (if they are not among 3DO's owners). All risk of technology ventures (such as 3DO) lie with the innovating company itself (and its owners). The manufacturers may increase their commitment by cooperating with the innovator. Cooperation can take two forms: they may form an alliance, or they may merge. In the latter case, the firm combines the R\&D and production processes. In the multimedia market, for example, Sony and Philips are competitors to 3DO. The former two develop their own operating systems (the PlayStation and CD-i, respectively), produce their own hardware and develop (some) of their software. To get that far, they acquired several companies. Sony motivated its acquisition of Columbia Pictures with reference to synergy with new electronic hardware (The Economist, 30-5-1992, p. 73). Alliances are a halfway house, providing more commitment than a market contract, but less so than a merger. The alliance above between Apple and Sharp is an example. Both bring in resources, and thus are to some extent committed to making their Newton work (for consumers as well). These examples suggest that market (licensing) contracts, mergers, and alliances can all be optimal ways of organising the transfer of know how.

On the theoretical side, D'Aspremont and Jacquemin (1988) have a seminal paper about the 
effects of competition, a merger, and an R\&D alliance. They study a horizontal merger or alliance, where there are two firms in the market, and each does R\&D. The firms may coordinate their $R \& D$ decisions, while continuing their independent $R \& D$ process (an $R \& D$ alliance), or they may coordinate both their R\&D and their output decisions (a merger). In the latter case, the market becomes a monopoly. There are technical reasons for cooperating in $R \& D$, as each firm's $R \& D$ leaks to the other firm (has a positive spillover effect). There are also strategic reasons, as R\&D affects marginal costs and thus one's competitive position relative to the competitor. Firms may also compete in $R \& D$ and in output levels. In a simple setting (constant returns to scale in production, a linear demand curve, and complete information), they show that the merger induces a higher $R \& D$ level than the alliance, and the alliance a higher $R \& D$ level than competition. The effect of this on the product market is that the alliance induces a higher aggregate output level than competition, which in turn induces a higher output level than the merger. De Bondt and Veugelers (1991, p. 358) add that the merger has a higher profit level than the alliance. This paper explores the results for the case of a vertical alliance between a research company and two manufacturing firms.

The papers about horizontal merger and alliances assume that the advantage of a merger is that it reduces competition in the product market. The social advantage of an alliance is that the participants continue to compete in the product market. Another oft noted advantage of an alliance is that it is a more flexible arrangement than a merger. Flexibility is an advantage if there is uncertainty. Firms appreciate some freedom to react to new information that resolves the uncertainty. To this end, the paper introduces uncertainty in the model. Firms do not want to commit to an innovator (e.g., by merging with him), if there is some chance that another technology emerges.

The IT examples all raise the question: how should the researcher and its manufacturing clients coordinate their decisions? The next sections compare a market contract to cooperation, i.e., a merger or alliance, between an innovator and two downstream (manufacturing) firms. It finds that cooperation stimulates aggregate output levels more than a market contract. But the market contract may (if $\mathrm{R} \& \mathrm{D}$ is relatively costly) be more profitable. It also finds that an alliance disappoints: it is usually less profitable than the other two forms, and always does less R\&D.

\section{The Model}

The product market is a Cournot duopoly with two manufacturing firms, F1 and F2. Their products are homogeneous and the inverse demand function is

(1) $\quad \mathrm{P}\left(\mathrm{q}_{1}+\mathrm{q}_{2}\right)=\mathrm{a}-\mathrm{b}\left(\mathrm{q}_{1}+\mathrm{q}_{2}\right)(\mathrm{a}, \mathrm{b}>0)$.

Marginal costs are $c_{i}$ for firm $\mathrm{i}(=1,2)$ (constant returns to scale). In the Cournot equilibrium, the output levels are:

(2) $q_{i}\left(c_{i}, c_{j}\right)=\frac{a+c_{j}-2 c_{i}}{3 b}(i, j=1,2 ; j \neq i)$.

The second order conditions hold for substitute products $(0<\mathrm{b})$. The industry output is 
(3) $\mathrm{Q}=\frac{2 a-c_{1}-c_{2}}{3 b}$.

The Cournot duopoly profits are:

(4) $\Pi_{i}\left(c_{i}, c_{j}\right)=\frac{\left(a+c_{j}-2 c_{i}\right)^{2}}{9 b}(i, j=1,2 ; j \neq i)$.

Initially, the marginal production costs are $c$, which expresses the current technology T0 (for technology). An innovator, R1, develops an innovation, T1, that may reduce the production cost, $\mathrm{c}$, by an amount $x$ (to $c-x$ ) at an $R \& D$ outlay: $R D=(\gamma / 2) x^{2}$ (D'Aspremont and Jacquemin, 1988). The parameter $\gamma$ indicates the costliness of R\&D: the lower $\gamma$ the more technologically dynamic the market will be. The model explores two time periods. The R\&D project starts at $t=0$. At $t=$ 1, the innovator R1 introduces its innovation. The market exhibits technological uncertainty: at a probability $\rho$, another innovation, $\mathrm{T} 2$, arrives that reduces the incumbent firm s' marginal costs to $c^{\text {' }}$ $(<c) .{ }^{2}$ The (successful) innovation by T2 is the only source of uncertainty in the market. The expressions when $\rho>0$ can be quite complicated. The main text gives the outcome when $\rho=0$, and the appendices give the results for the more general case (where $0 \leq \rho \leq 1$ ).

For reasons that become transparent later on, it is useful to make some simplifying assumptions on $\mathrm{a} / \mathrm{c}$ and $\gamma \mathrm{b}$ :

(5) $2<\mathrm{a} / \mathrm{c}$.

(6) $2 / 3 a / c<\gamma b$.

These two assumptions combined imply that $4 / 3<\gamma b$. Furthermore:

(7) $(7 / 9) a / c-5 / 9 \leq \gamma b$.

The game sequence is as follows. In the first period, the innovator and the manufacturing firms choose a way to organize the transfer of know how. Given a particular organisation, the innovator R1 decides about its $\mathrm{R} \& \mathrm{D}(\mathrm{x})$. At the beginning of the next period, $\mathrm{T} 2$ does or does not arrive into the market. Observing this, the innovator R1 introduces its innovation. It announces a license fee or uses another mechanism to transfer its know how to the manufacturing firms. Given the arrival of T2, the innovation T1, and the license fee or other arrangement, the manufacturing firms adopt a technology. The technology chosen and the way the innovator and the manufacturing firms organize the transfer of know how, determine the firms' actual marginal costs $\left(c_{i}, c_{j}\right)$. Given these costs, the firms compete in the product market. (Technically, this is a four-stage game).

The results that we are interested in are the level of $R \& D$ effort $(x)$, the expected (at $t=0$ ) aggregate output level $(\mathrm{Q})$ of the two manufacturing firms, and the expected joint profit $\left(\Pi^{\mathrm{J}}\right)$ of the

2. The marginal cost c' may include an exogenous license fee. Alternatively, T2 may be an improvement of T0 (e.g., by learning). 
three firms (at the beginning of the game, $\mathrm{t}=0$ ). The next sections study three ways in which $\mathrm{R} 1$, F1, and F2 may organise their R\&D: a market transfer or contract, a merger between the innovator and a manufacturing firm, and an alliance among the innovator and both manufacturing firms.

\section{The Market Transaction}

In the market transaction the manufacturing firms wait until the innovation is introduced in the market. They compare the offer by the innovator (that consists of an innovation and a license fee) with the competing technology $\mathrm{T} 2$, if it arrived, and the existing technology T0. They adopt the technology that offers the lowest marginal costs. The innovator R1 thus carries the entire risk of its innovation. The manufacturers 'buy' technology in the market place whenever it comes available (in the second period of the game).

In the first period of the game, the innovator chooses its $\mathrm{R} \& \mathrm{D}$ level, $x$, that reduces the marginal production cost to c-x. In the second period it offers the new technology to the users with a (per unit) license fee, $l$. The users F1 and F2 have marginal costs of $c-x+l$ if they use T1. They adopt T1 if the associated marginal cost is less than $c$ (of T0) and $c^{`}$ (of T2, if it arrives). Equations (2) and (4) give their output levels and profits, respectively. In the beginning of the second period, the innovator observes whether $\mathrm{T} 2$ entered the market, and then decides on its unit license fee, $l$. Anticipating this in the first period, the innovator chooses the R\&D effort that maximizes its expected profits:

$$
\Pi_{\mathrm{R} 1}=\delta 1\left(\mathrm{q}_{1}+\mathrm{q}_{2}\right)-(\gamma / 2) \mathrm{x}^{2}
$$

where the discount rate $\delta=1 /(1+\mathrm{r})$. For convenience, assume that $\mathrm{r}=0$ and $\delta=1$.

\subsection{The Second Period}

The innovator faces one of three cases when choosing its license fee. Case 1 occurs if T2 does not appear. In this case, R1 chooses the profit maximizing license fee that just deters firms 1 and 2 from staying with their existing technology: $\mathrm{c}-\mathrm{x}+1 \leq \mathrm{c}$, i.e.., $1 \leq \mathrm{x}$. If $\mathrm{T} 2$ does enter the market, $\mathrm{R} 1$ may try to undercut its offer ( $\left.c^{\prime}\right)$ if $\mathrm{c}-\mathrm{x}<\mathrm{c}^{\prime}$. This is case 2, where we shall call the rival's innovation non-drastic. The innovator $\mathrm{R} 1$ can demand a license fee 'just' below c': $\mathrm{c}-\mathrm{x}+1 \leq \mathrm{c}^{\prime}$, i.e., $1 \leq \mathrm{x}+\mathrm{c}^{\prime}-\mathrm{c}$. Case 3 holds if instead, $\mathrm{c}-\mathrm{x} \geq \mathrm{c}^{\prime}$. The rival innovator leapfrogs the innovator $\mathrm{R} 1$, and firms 1 and 2 switch to T2. Firm R1's license fee is zero. Call the rival innovation drastic.

The optimal license fee is:

$\mathrm{x}$, for all $0 \leq \mathrm{x}<\mathrm{c}$ in case 1 (T2 does not arrive);

(9) $1=x+c^{\prime}-c$, if $c-c^{\prime}<x \leq c$ (case 2, T2 arrives and is non-drastic);

0 , if $0 \leq \mathrm{x} \leq \mathrm{c}^{-c^{\prime}}$ (case 3, T2 arrives and is drastic).

(Proof: see appendix A). As figure 1 illustrates, the licensee fee is everywhere larger if T2 does not arrive than if it does. The license fee raises the marginal costs of the manufacturing firms to their next best alternative (which is either $\mathrm{c}$ or $\mathrm{c}^{\prime}$ ): 
$\mathrm{c}$, if $\mathrm{T} 2$ does not arrive (case 1);

(10) $\mathrm{c}_{\mathrm{i}}=$

$c^{\prime}$, if $\mathrm{T} 2$ does arrive (cases 2 and 3 ).

The manufacturing firms' output and profit levels follow from substituting equation (10) in equations (2) and (4), respectively. The innovator's (R1) innovation has no effect at all on the marginal costs, due to R1's license policy. The license revenue of the innovator is:

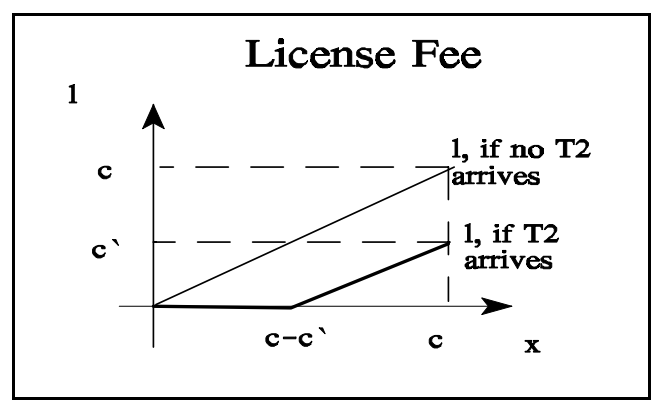

Figure 1

$2 x(a-c) / 3 b$ (case 1$)$

(11) $\mathrm{L}=2\left(\mathrm{x}+\mathrm{c}^{\prime}-\mathrm{c}\right)\left(\mathrm{a}-\mathrm{c}^{\prime}\right) / 3 \mathrm{~b}$, if $\mathrm{c}-\mathrm{c}^{\prime}<\mathrm{x}<\mathrm{c}($ case 2$)$;

0 , if $\mathrm{x} \leq \mathrm{c}-\mathrm{c}^{\prime}$ (case 3 ).

\subsection{The First Period}

Given the expected license revenues, the innovator chooses its R\&D strategy in the first period. Its overall profit, $\Pi_{c}{ }^{R 1}$, equals $\delta \mathrm{E}(\mathrm{L})-\mathrm{RD}$, where $\mathrm{RD}=(\gamma / 2) \mathrm{x}^{2}$, and $\delta=1$, for convenience. The subscripts $c, m$, and $a$ will refer to the market contract, merger, and alliance, respectively. At $\mathrm{t}=0$, the expected license revenue depends on the outcome in the second period if $\mathrm{T} 2$ does not arrive

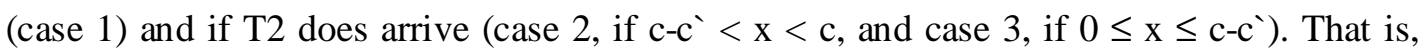

(12) $\Pi_{\mathrm{c}}^{\mathrm{R} 1}=$

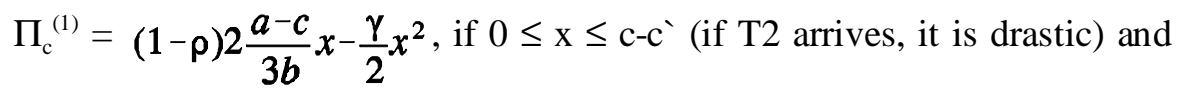

$$
\begin{aligned}
& \Pi_{\mathrm{c}}^{(2)}=\rho 2 \frac{a-c^{\prime}}{3 b}\left(x+c^{`}-c\right)+(1-\rho) 2 \frac{a-c}{3 b} x-\frac{\gamma}{2} x^{2}, \text { if } \mathrm{c}^{-} \mathrm{c}^{`}<\mathrm{x}<\mathrm{c} \text { (if } \mathrm{T} 2 \text { arrives it is non- } \\
& \text { drastic). }
\end{aligned}
$$

This function is continuous in $x$, but not continuously differentiable. We are now ready for some results. The text of the paper reports the results for the special case where $\rho=0$, i.e., the rival technology, T2, does not arrive; see appendix B for the general case.

\subsection{Results for the market contract}

In the first period, the innovator chooses the profit maximizing $R \& D$ effort, $x$, subject to the constraints $0 \leq \mathrm{x}<\mathrm{c}$ :

(13) $\mathrm{x}_{\mathrm{c}}^{*}=2 \frac{a-c}{3 \gamma b}$.

The second order condition holds if $\gamma>0$. Substitute equation (13) into equation (12) for the 
innovator's optimal expected profits at $\mathrm{t}=0$ :

(14) $\Pi_{\mathrm{c}}^{\mathrm{R} 1^{*}}=2 \frac{(a-c)^{2}}{9 b^{2} \gamma}$.

Due to equation (10), the aggregate output level by the manufacturing firms, Q, does not depend on the innovator's R\&D. From equation (3) follows:

(15) $\mathrm{Q}_{\mathrm{c}}{ }^{*}=2(\mathrm{a}-\mathrm{c}) / 3 \mathrm{~b}$.

The profits of firms 1 and $2, \Pi_{\mathrm{i}}$, are $(\mathrm{a}-\mathrm{c})^{2} / 9 \mathrm{~b}$ (equation 4). Add their profits to $\Pi_{\mathrm{c}}^{\mathrm{R}{ }^{*}}$ in equation (14) for the expected (at $t=0)$ joint profit, $\Pi_{c}{ }^{*}$ :

(16) $\Pi_{\mathrm{c}}^{\mathrm{J}^{*}}=\frac{2(a-c)^{2}}{9 b^{2} \gamma}(1+\gamma b)$.

In this section, the manufacturing firms have a non-committal attitude to the innovation. They shop for technologies. In the next two sections, the manufacturers tie themselves to the innovator in the first period, before the innovation is concluded and before the uncertainty about T2 is resolved. The firms share some commitment, therefore. There are two instruments to do so: a merger with the innovator, or an alliance. The next section explores the merger.

\section{A Vertical Merger}

Firms R1 and F1 (say) merge. ${ }^{3}$ After its merger, R1 may license the innovation to F2, while F2 can also choose T0 and the alternative innovation T2 (if available). The merged manufacturer, F1, also still has the freedom to switch to $\mathrm{T} 2$, if available. The model shows why the merger, notwithstanding this freedom of F1, does enlarge the manufacturing firm's commitment to T1. This larger commitment in turn may give the innovator (in the merged firm) a larger incentive to innovate, to the advantage of one or both manufacturing firms.

\subsection{The Second Period}

In this period, the merged firm chooses a license fee to firm F2 (1), and both manufacturing firms then choose output levels. As before, there are three cases: T2 does not arrive (case 1), T2 does arrive, and is non-drastic ( $-\mathrm{x}<\mathrm{c}^{\prime}$, case 2), and T2 arrives and is drastic ( $c^{\prime}<\mathrm{c}-\mathrm{x}$, case 3$)$. The marginal cost of firm F1, $c_{1}$, equals $c-x$ or $c^{\prime}$, whichever is lower. Notwithstanding its merger with $\mathrm{R} 1$, the manufacturing division, $\mathrm{F} 1$, is free to switch from $\mathrm{T} 1$ to $\mathrm{T} 2$. The merger does reduce the marginal cost associated with the innovation $\mathrm{T} 1$ from $\mathrm{c}-\mathrm{x}+\mathrm{l}$ (in the market transaction) to $\mathrm{c}-\mathrm{x}$ (in

3. An alternative model might be where R1 merges with F1 and F2. It seems likely that antitrust would step in the way of this development. I thus ignore it. 
the merger). By reducing the marginal cost associated with $\mathrm{T} 1$, the merger raises the commitment of F1 to T1. Because of this effect, the merger may have different dynamic outcomes than the market contract. It follows that

c-x (in cases 1 and 2); and

(17) $\mathrm{c}_{1}=$

$c^{\prime}$ (in case 3).

The marginal cost of firm $2, \mathrm{c}_{2}$, equals $\min \{\mathrm{c}-\mathrm{x}+\mathrm{l}, \mathrm{c}\}$, if $\mathrm{T} 2$ does not arrive, and $\mathrm{c}_{2}=\min \left\{\mathrm{c}-\mathrm{x}+1, \mathrm{c}^{\prime}\right\}$, if $\mathrm{T} 2$ does arrive. If $\mathrm{c}-\mathrm{x}<\mathrm{c}^{\prime}$ (case 2), the innovator can choose a license fee that induces firm 2 to use $\mathrm{T} 1$ rather than $\mathrm{T} 2$ :

$\mathrm{c}-\mathrm{x}+\mathrm{l}$, where $1 \leq \mathrm{x}$ (in case 1$)$;

(18) $c_{2}=c-x+1$, where $1 \leq x+c^{\prime}-c($ case 2$)$;

$c^{\prime}$ (in case 3).

The merged firm's gross profit is $\left(\mathrm{p}-\mathrm{c}_{1}\right) \mathrm{q}_{1}+\mathrm{lq}_{2}$. Substitute equation (17) and (18) in equation (2) for the output levels:

$(\mathrm{a}-\mathrm{c}+\mathrm{x}+1) / 3 \mathrm{~b}$ (in cases 1 and 2$)$; and

(19a) $\quad \mathrm{q}_{1}=$

$\left(\mathrm{a}-\mathrm{c}^{\prime}\right) / 3 \mathrm{~b}$ (in case 3$)$.

$(\mathrm{a}-\mathrm{c}+\mathrm{x}-2 \mathrm{l}) / 3 \mathrm{~b}$ (in cases 1 and 2); and

(19b) $\quad \mathrm{q}_{2}=$

$\left(a-c^{\prime}\right) / 3 b$ (in case 3$)$.

Due to equation (18), the upper bound on $l$ is $\mathrm{x}$, if $\mathrm{T} 2$ does not arrive, and $\mathrm{x}+\mathrm{c}^{\prime}-\mathrm{c}$, if $\mathrm{T} 2$ does arrive (and is non-drastic, i.e., $\mathrm{c}^{\prime} \geq \mathrm{c}-\mathrm{x}$ ). Call the upper bound $k$. Anticipating this, the merged firm chooses $l$ for cases 1 and 2 in the following Kuhn-Tucker problem:

(20) $\operatorname{Max}_{1} \Pi_{1}=\frac{(a-c+x+l)^{2}}{9 b}+l \frac{a-c+x-2 l}{3 b}$, subject to $\mathrm{k} \geq 1$ and $1 \geq 0$.

This gives the same results as equation (9). The table gives the results for the three cases: 


\begin{tabular}{||l|l|l|l||}
\hline \hline & $\begin{array}{l}\text { Case 1 } \\
(\text { No T2 })\end{array}$ & $\begin{array}{l}\text { Case } 2 \\
\left(T 2, c^{\prime} c^{\prime}<x \leq c\right)\end{array}$ & $\begin{array}{l}\text { Case 3 } \\
\left(T 2,0<x \leq c^{\prime}\right)\end{array}$ \\
\hline $1=k$ & $\mathrm{x}$ & $\mathrm{x}^{\prime}-\mathrm{c}$ & $(-)$ \\
\hline $\mathrm{c}_{1}$ & $\mathrm{c}-\mathrm{x}$ & $\mathrm{c}-\mathrm{x}$ & $\mathrm{c}^{\prime}$ \\
\hline $\mathrm{c}_{2}$ & $\mathrm{c}$ & $\mathrm{c}^{\prime}$ & $\mathrm{c}^{\prime}$ \\
\hline $\mathrm{q}_{1}$ & $(\mathrm{a}-\mathrm{c}+2 \mathrm{x}) / 3 \mathrm{~b}$ & $\left(\mathrm{a}-2 \mathrm{c}+\mathrm{c}^{\prime}+2 \mathrm{x}\right) / 3 \mathrm{~b}$ & $\left(\mathrm{a}-\mathrm{c}^{\prime}\right) / 3 \mathrm{~b}$ \\
\hline $\mathrm{q}_{2}$ & $(\mathrm{a}-\mathrm{c}-\mathrm{x}) / 3 \mathrm{~b}$ & $\left(\mathrm{a}+\mathrm{c}-2 \mathrm{c}^{\prime}-\mathrm{x}\right) / 3 \mathrm{~b}$ & $\left(\mathrm{a}-\mathrm{c}^{\prime}\right) / 3 \mathrm{~b}$ \\
\hline $\mathrm{Q}$ & {$[2(\mathrm{a}-\mathrm{c})+\mathrm{x}] / 3 \mathrm{~b}$} & {$\left[2 \mathrm{a}-\mathrm{c}-\mathrm{c}^{\prime}+\mathrm{x}\right] / 3 \mathrm{~b}$} & $2\left(\mathrm{a}-\mathrm{c}^{\prime}\right) / 3 \mathrm{~b}$ \\
\hline$\Pi_{1}$ & {$\left[(\mathrm{a}-\mathrm{c})^{2}+7(\mathrm{a}-\mathrm{c}) \mathrm{x}+\mathrm{x}^{2}\right] / 9 \mathrm{~b}$} & $\begin{array}{l}{\left[(\mathrm{a}-\mathrm{c})^{2}+7(\mathrm{a}-\mathrm{c}) \mathrm{x}-5(\mathrm{a}-\mathrm{c})\left(\mathrm{c}-\mathrm{c}^{\prime}\right)+\mathrm{x}^{2}+5 \mathrm{x}(\mathrm{c}\right.} \\
\left.\left.-\mathrm{c}^{\prime}\right)-5\left(\mathrm{c}-\mathrm{c}^{\prime}\right)^{2}\right] / 9 \mathrm{~b}\end{array}$ & $\left(\mathrm{a}-\mathrm{c}^{\prime}\right)^{2} / 9 \mathrm{~b}$ \\
\hline$\Pi_{2}$ & $(\mathrm{a}-\mathrm{c}-\mathrm{x})^{2} / 9 \mathrm{~b}$ & {$\left[\mathrm{a}+\mathrm{c}-2 \mathrm{c}^{\prime}-\mathrm{x}\right]^{2} / 9 \mathrm{~b}$} & $\left(\mathrm{a}-\mathrm{c}^{\prime}\right)^{2} / 9 \mathrm{~b}$ \\
\hline
\end{tabular}

This concludes the second period.

\subsection{The First Period}

In the first period, firm 1 chooses its $\mathrm{R} \& \mathrm{D}$ effort, $\mathrm{x}$. The expected profits of the merged firm are (for $\rho=0$, see appendix $C$ for the general case):

(21) $\Pi_{\mathrm{m} 1}=\frac{1}{9 b}\left[(a-c)^{2}+7(a-c) x+x^{2}\right]-\frac{\gamma}{2} x^{2}$.

\subsection{Results for the merger}

In the first period, the merged firm chooses the optimal R\&D effort:

(22) $\mathrm{x}_{\mathrm{m}}{ }^{*}=\frac{7}{9 \gamma b-2}(a-c)$.

The second order condition holds if $2-9 \gamma b<0$, which follows from equations (5) and (6). The marginal cost, $c-x_{m}$, is positive for all $\rho$ if and only if $a / c \leq(9 \gamma b+5) / 7$, which accords with equation (7). Substitute equation (22) in (21) for the maximum expected profit levels attained by the merged firm:

(23) $\Pi_{\mathrm{m} 1}{ }^{*}=\frac{2 \gamma b+5}{2 b(-2+9 \gamma b)}(a-c)^{2}$. 
The expected aggregate output level at $t=0, Q_{m}$, equals (see the table above):

(24) $\mathrm{Q}_{\mathrm{m}}=[2(\mathrm{a}-\mathrm{c})+\mathrm{x}] / 3 \mathrm{~b}$.

Substitute the appropriate levels of R\&D effort, from equation (22), in equation (24):

(25) $\mathrm{Q}_{\mathrm{m}}{ }^{*}=\frac{1+6 \gamma b}{b(-2+9 \gamma b)}(a-c)$.

To find the expected joint profit of all three firms, we first identify the expected profit of fim 2 . In similar fashion as with $\mathrm{Q}_{\mathrm{m}}$, this gives:

(26) $\Pi_{\mathrm{m} 2}=\frac{(a-c-x)^{2}}{9 b}$.

Substitute the appropriate levels of R\&D effort, from equation (22), in equation (26):

(27) $\Pi_{\mathrm{m} 2}{ }^{*}=\frac{9(-1+\gamma b)^{2}}{b(-2+9 \gamma b)^{2}}(a-c)^{2}$.

Add the expected profit of firm 2 to the expected profit of the merged firm for the expected joint profit at $\mathrm{t}=0$ for all three firms:

(28) $\Pi_{\mathrm{m}}^{\mathrm{J}^{*}}=\frac{8+5 \gamma b+36 \gamma^{2} b^{2}}{2 b(-2+9 \gamma b)^{2}}(a-c)^{2}$.

\section{An R\&D Alliance}

The third cooperation arrangement in this paper is the $R \& D$ alliance. The alliance chooses the R\&D level that maximizes the joint profits of the three firms (R1, F1 and F2). The manufacturing firms then compete with each other in the product market (at marginal costs of c-x, if they adopt the alliance's innovation). Like the merger, this represents some commitment by the manufacturing firms, as they participate in the alliance before the results of the innovation are there, and before uncertainty about $\mathrm{T} 2$ is resolved. Like in the previous case, the manufacturing firms are free to adopt $\mathrm{T} 2$ if this is profitable for them. ${ }^{4}$

An alliance is, of course, based on a contract that specifies behaviour or incentives. The induced behaviour of the partners may or may not maximize their joint interest. A bargaining process will distribute the aggregate profits over the three firms. Following other papers (e.g.,

4. It follows that an alliance between the innovator and one manufacturing firm would be identical to the merger. This is why the paper ignores that possibility. 
D'Aspremont and Jacquemin, 1988), neither the contract nor the bargaining is specified, that is, joint profit maximization is postulated rather than proven. The model is, therefore, not descriptively correct, but its predictions provide the upper bound to what an alliance, with a specified contract, might achieve. ${ }^{5}$

Firms F1 and F2 compete in the product market with identical marginal costs:

$\mathrm{c}-\mathrm{x}$, if $\mathrm{T} 2$ does not arrive (case 1) or if a non-drastic T2 arrives (case $2, \mathrm{c}^{\prime} \mathrm{c}^{\prime} \leq \mathrm{x} \leq \mathrm{c}$ );

(29) $\mathrm{c}_{\mathrm{i}}=$

$c^{\prime}$, if a drastic T2 arrives (case 3, $\left.0 \leq \mathrm{x}<\mathrm{c}-\mathrm{c}^{\prime}\right)$.

The gross profits are:

$$
\left.\frac{(a-(c-x))^{2}}{9 b} \text { (case } 1 \text { and case } 2\right)
$$

(30) $\Pi_{\mathrm{i}}=$

$$
\frac{\left(a-c^{\prime}\right)^{2}}{9 b}(\text { case } 3)
$$

The joint profit of the three firms in the alliance is:

(31) $\Pi_{\mathrm{a}}^{\mathrm{J}}=$

$$
\left.\Pi_{\mathrm{a}}^{\mathrm{J}(1)}=\rho 2 \frac{\left(a-c^{\prime}\right)^{2}}{9 b}+(1-\rho) 2 \frac{(a-c+x)^{2}}{9 b}-\frac{\gamma}{2} x^{2} \text {, if } 0 \leq \mathrm{x}<\mathrm{c}-\mathrm{c}^{\prime} \text { (cases } 1 \text { and } 3\right) ;
$$

$$
\Pi_{\mathrm{a}}^{\mathrm{J}(2)}=2 \frac{(a-c+x)^{2}}{9 b}-\frac{\gamma}{2} x^{2}, \text { if } \mathrm{c}-\mathrm{c}^{\prime} \leq \mathrm{x} \leq \mathrm{c}(\text { cases } 1 \text { and } 2) .
$$

As before, this is continuous, and quadratic in $\mathrm{x}$. The results are as follows.

\subsection{The results of the alliance}

In the first period, the alliance chooses the joint profit maximizing level of $R \& D$ effort. Maximize equation (31) for $\rho=0$ :

5. Since the foundation of the alliance is a contract, one should ideally demonstrate that a contract exists that induces these effects. If the contract specifies a license fee, results might be more akin to the market contract. Unlike in a market contract, however, in an alliance the manufacturing firms may acquire an interest in the innovator. Both firms may own the innovator (i.e., R1 is a research joint venture of F1 and F2). In that case, the license fee is also a source of profits to them. This would transform part of the license fees into a marginal revenue rather than a cost. Hence, the firms' marginal costs would fall from $c-x+1$ (market contract) down to $c-x$ (alliance in the paper). The case in this paper, where firms' marginal costs are equal to c-x, is thus an 'ideal' case, that firms may reach by a combination of license fees and shares in the innovator. I leave this to another paper. 
(32) $\mathrm{x}_{\mathrm{a}}^{*}=\frac{4(a-c)}{9 \gamma b-4}$.

The R\&D level is positive, and the second order condition holds, as $9 \gamma b-4>0$ (from equations 5 and 6). The associated maximum joint profit is

(33) $\Pi_{\mathrm{a}}^{\mathrm{J}^{*}}=\frac{2 \gamma(a-c)^{2}}{9 \gamma b-4}$.

(See appendix D). Positive R\&D and output levels imply the assumption that $(4 / 9)(a / c) \leq \gamma b$, which holds due to equation (6).

Due to equation (29), $c_{1}=c_{2}=c-x$, if $\rho=0$ (see appendix D for the case when T2 may enter the market, i.e., when $0<\rho)$. This implies that

(36) $\mathrm{Q}_{\mathrm{a}}=2 \frac{a-c+x}{3 b}$.

Substitute the R\&D effort level from equation (32) in the output level Q:

(37) $\mathrm{Q}^{*}=\frac{6 \gamma(a-c)}{9 \gamma b-4}$.

This completes the computations for the three modes of organising R\&D. I will now compare their outcomes.

\section{Comparing the Market, Merger, and Alliance}

In this section we look at the marginal costs, the R\&D effort levels, the aggregate output level, and the joint profit level of the three firms.

\subsection{The marginal cost levels}

First compare the pair of marginal costs $\left(c_{1}, c_{2}\right)$ in the second period (with endogenous license fee, $l$, and a given $\mathrm{R} \& \mathrm{D}$ effort $x$ ). See the table.

\begin{tabular}{||l|l|l|l||}
\hline & $\begin{array}{l}\text { Case 1 } \\
\text { (No T2) }\end{array}$ & $\begin{array}{l}\text { Case 2 } \\
\text { (Non-drastic T2: c-x < c') }\end{array}$ & $\begin{array}{l}\text { Case 3 } \\
(\text { Drastic T2: c' < c-x })\end{array}$ \\
\hline Market & $(\mathrm{c}, \mathrm{c})$ & $\left(\mathrm{c}^{\prime}, \mathrm{c}^{\prime}\right)$ & $\left(\mathrm{c}^{\prime}, \mathrm{c}^{\prime}\right)$ \\
\hline Merger & $(\mathrm{c}-\mathrm{x}, \mathrm{c})$ & $\left(\mathrm{c}-\mathrm{x}, \mathrm{c}^{\prime}\right)$ & $\left(\mathrm{c}^{\prime}, \mathrm{c}^{\prime}\right)$ \\
\hline Alliance & $(\mathrm{c}-\mathrm{x}, \mathrm{c}-\mathrm{x})$ & $(\mathrm{c}-\mathrm{x}, \mathrm{c}-\mathrm{x})$ & $\left(\mathrm{c}^{\prime}, \mathrm{c}^{\prime}\right)$ \\
\hline
\end{tabular}

This comparison shows that there is no difference if a drastic T2 arrives. Note that the cooperation 
form has an effect on $\mathrm{x}$, and thus determines whether a particular $\mathrm{c}^{\prime}$ is 'drastic'. In case 1, the market has the highest marginal costs for both fims (as $c>c-x$ ). The alliance has the lowest marginal costs for both firms. The merger is an intermediate case: it has the lowest marginal cost for firm 1 but the highest marginal cost for firm 2. The same holds for case 2 (where $c-x<c^{\prime}$ ).

The merger is efficient, compared to the market, as it chooses the output level of firm F1 on the basis of the marginal production cost, c-x, rather than on the markup, $l$, that the innovator imposes on top of the marginal production cost, c-x. This is the standard (double marginalization) explanation of the efficiency of a vertical merger. That the merged firm raises the marginal cost of firm F2 to the highest level acceptable (c, in case 1, and c' in case 2) is an example of a price squeeze (Salinger, 1988). The merged firm supplies an input to F2 (know how) while competing with it in the product market (through F1). Thus it raises the input price to F2 (the license fee) to the maximum that it can extract. The alliance is even more efficient than the merger by the same argument, as it succeeds in reducing the marginal costs of both firms to the marginal production cost.

\subsection{The R\&D effort}

Compare equations (13), (22), and (32) to find:

Proposition 1 (Optimal R\&D effort levels): $\mathrm{x}_{\mathrm{a}}<\mathrm{x}_{\mathrm{c}}<\mathrm{x}_{\mathrm{m}}$.

This result also holds in the case of technological uncertainty (proof: see appendix F). The result about the alliance may be a surprise, as an alliance is usually presented as a way to stimulate R\&D. The European joint R\&D programmes were started on this assumption. However, as Martin (1993, p. 376) notes, R\&D joint ventures are socially advantageous not because they encourage R\&D but because they encourage firms to compete in the use of new technology after it is discovered. So let's turn to the effects on the aggregate output level (and by implication, the market price).

\subsection{The aggregate output level}

The expected (at $\mathrm{t}=0$ ) output levels of the market contract, merger and alliance $\left(\mathrm{Q}_{\mathrm{c}}, \mathrm{Q}_{\mathrm{m}}, \mathrm{Q}_{\mathrm{a}}\right.$ ) in equations (20), (30) and (37), when compared give:

Proposition 2 (Optimal aggregate output levels): $\mathrm{Q}_{\mathrm{c}}<\mathrm{Q}_{\mathrm{m}}<\mathrm{Q}_{\mathrm{a}}$.

(Proof: see appendix G). Numerical simulations show that in all cases (including positive $\rho$ 's), it holds that $\mathrm{Q}_{\mathrm{c}}<\mathrm{Q}_{\mathrm{m}}$. It is obvious that the aggregate output level of the market contract is the smallest. In that case, the innovator imposes a license fee upon the manufacturing fims such that their marginal cost does not fall. Hence, the R\&D does not induce them to increase their output level. The two modes of R\&D cooperation do reduce the firms' marginal cost levels, and thus raise their aggregate output level. If there is a positive probability that $\mathrm{T} 2$ does arrive $(0<\rho)$, then cases exist where $Q_{m}>Q_{a}$. These are cases with intermediate values of c' (in between 0 and $c$ ), 
where there is technological uncertainty and the rival technology is a moderate improvement over the current technology. Since the cumulative output level determines the market price, the merger can be advantageous for consumers.

\subsection{The joint profit level ${ }^{6}$}

Compare the expected joint profit level of all three firms of the three modes of cooperation, $\Pi_{c}^{J^{*}}$, $\Pi_{\mathrm{m}}^{\mathrm{J}^{*}}$, and $\Pi_{\mathrm{a}}^{\mathrm{J}^{*}}($ when $\rho=0)$ :

Proposition 3 (Joint profit levels): $\Pi_{\mathrm{a}}^{\mathrm{J}^{*}}<\Pi_{\mathrm{m}}^{\mathrm{J}^{*}}$ and $\Pi_{\mathrm{a}}^{\mathrm{J}^{*}}<\Pi_{\mathrm{c}}^{\mathrm{J}^{*}}$.

(See appendix H). Thus, collectively, the three firms can improve upon an alliance by a bilateral merger or by a market contract. Which of the latter is the more profitable depends on the expression $\gamma b$ :

Proposition 4 (Joint profit level of merger and market contract): If $1 \frac{1}{3}<\gamma b<20 / 27+(28 / 135) \sqrt{ } 10$ ) $(\approx 1.397)$, then the merger is more profitable $\left(\Pi_{\mathrm{c}}^{\mathrm{J}^{*}}<\Pi_{\mathrm{m}}^{\mathrm{J}}\right)$. For larger values of $\gamma \mathrm{b}$, the market contract is more profitable.

(See appendix H). The lower bound to $\gamma b\left(1 \frac{1}{3}\right)$ follows from equation (6) and $2<\mathrm{a} / \mathrm{c}$. The parameter $\gamma$ indicates the costliness of R\&D. Hence, in a dynamic environment (low $\gamma$ ), the firms benefit from a merger. In a less dynamic environment (higher $\gamma$ ), market contracts are collectively more profitable. If uncertainty is allowed $(0<\rho)$, appendix $\mathrm{H}$ finds that the merger is 'usually' more profitable than the alliance.

The table reports a simulation where $a c(=a-c)=1, b=1$, and $\rho=0.5$. The simulation runs several values of $\mathrm{dc}\left(=\mathrm{c}-\mathrm{c}^{\prime}\right)$

\begin{tabular}{|c|c|c|c|c|c|c|c|c|c|c|c|}
\hline 0 & 1.343 & 1.454 & 1.506 & 1.677 & 1.788 & 1.899 & 2.01 & 2.121 & 2.232 & 2343 & and $\gamma$. Since $c^{\prime}<c$, it holds \\
\hline 0.01 & 2 & 2 & 2 & 2 & 2 & 2 & 2 & 2 & 2 & 2 & $<$ dc. From \\
\hline 0110 & 2 & 2 & 2 & 2 & 2 & 2 & 2 & 2 & 2 & 2 & ws that $\mathrm{dc}<\mathrm{ac}(=$ \\
\hline 0.228 & 2 & 2 & 2 & 2 & 2 & 2 & 2 & 2 & 1 & 1 & 1). Equations (5) and (6) \\
\hline 0.337 & 2 & 2 & 2 & 1 & 1 & 1 & 1 & 2 & 2 & 2 & imply that $1.333<\gamma$ (for $\mathrm{b}=$ \\
\hline 0.446 & 1 & 1 & 1 & 2 & 2 & 2 & 2 & 2 & 2 & 2 & 1). The left column shows \\
\hline 0.554 & 1 & 2 & 2 & 2 & 2 & 2 & 2 & 2 & 2 & 2 & the values of dc simulated, \\
\hline 0.603 & 2 & 2 & 2 & 2 & 2 & 2 & 2 & 2 & 2 & 2 & from 0.01 to 0.99 . The top \\
\hline 0.772 & 2 & 2 & 2 & 2 & 2 & 2 & 2 & 2 & 2 & 2 & row shows the values of $\gamma$ \\
\hline 0881 & 2 & 2 & 2 & 2 & 2 & 2 & 2 & 2 & 2 & 2 & from 1.343 to \\
\hline by & 2 & 2 & 2 & 2 & 2 & 2 & 2 & 2 & 2 & 1 & \\
\hline
\end{tabular}

6. The reason for focusing on the joint profit level is that the choice between market contract, merger, and alliance involves all three firms. Their bargaining may achieve the outcome that realizes the highest joint profits (the Coase theorem). Share prices (here implicit) and license fees can be the instruments in this bargaining. 
to the situation where $\Pi_{\mathrm{a}}^{\mathrm{J}^{*}}=\Pi_{\mathrm{m}}^{\mathrm{J}^{*}}$, a '1' refers to $\Pi_{\mathrm{a}}^{\mathrm{J}^{*}}>\Pi_{\mathrm{m}}^{\mathrm{J}^{*}}$, and a '2' to $\Pi_{\mathrm{a}}^{\mathrm{J}^{*}}<\Pi_{\mathrm{m}}^{\mathrm{J}^{*}}$. The '2's in the table show the preference for the merger. An alliance has a higher joint profit for intermediate values of $\mathrm{dc}$ (and thus intermediate values of $\mathrm{c}^{\prime}$ between 0 and $\mathrm{c}$ ). For higher values of $\gamma$, the value of $\mathrm{dc}$ for which the alliance is more profitable decreases. These are cases where the rival's innovation is drastic for the alliance and non-drastic for the merger: $\mathrm{c}-\mathrm{x}_{\mathrm{m}}{ }^{*}<\mathrm{c}^{\prime}<\mathrm{c}-\mathrm{x}_{\mathrm{a}}{ }^{*}$. The merger does more R\&D than the alliance, and so much so that it hurts the profits of firm F2 (the price squeeze) and thereby reduces the joint profits. Alliances thus emerge only if there is some uncertainty (for otherwise proposition 3 holds), and if the alternative technology is neither very efficient ( $c^{`}$ low, dc high) nor a marginal improvement (where $c^{\prime}$ is close to $c$, and $\mathrm{dc}$ is close to zero). The association of alliances with technological uncertainty seems an intuitive result.

\section{Appraisal}

This paper finds some clear-cut results when firms buy technology in the market or, alternatively, cooperate with a research company. Cooperation is better than a market transaction in that a merger gives a higher R\&D outlay than a market contract, and both the merger and the alliance give higher output levels than the market. Because of the latter, cooperation reduces prices relative to the market contract, and thus benefits consumers. The market contract may, however, give rise to the largest cumulative profits of the three firms. Although beneficial to consumers, therefore, cooperation may not emerge.

Proposition 4 gives the intuitive result that if markets become more dynamic (in that the effectiveness of doing R\&D increases or its costliness decreases), then market contracts may give way to mergers. This gives a meaningful explanation of why new developments in information technology, such as multimedia and interactive television, induce a spate of mergers and acquisitions. A new technological phenomenon, the digitization process, has turned the media into fundamentally more technologically dynamic markets. Hollywood and Silicon Valley are about to converge (into Sillywood, as insiders believe). This process underlies mergers, as insiders claim and this model substantiates.

Proposition 3 has the result that an alliance is less profitable than the alternatives (if there is no technological uncertainty). This is rather unexpected. Judging by the cumulative profits, therefore, firms will never form an alliance, and either merge or conclude a market contract. The analysis in D'Aspremont and Jacquemin (1988) also led to the conclusion that a merger is more profitable than an $R \& D$ alliance. The merger is more profitable than the alliance because it increases market power by creating a monopoly. In this paper, the merger and alliance are vertical, between downstream manufacturers and an upstream research company. The product market is not monopolised. Nevertheless, in an indirect way, the merger creates market power too. The merger creates an asymmetry between the marginal cost of the acquired manufacturing firm (whose marginal cost falls from $c$ to $c-x$ ) and the non-acquired firm (whose marginal cost remains at $c$, as the license fee absorbs the cost reduction by the innovation). The cost asymmetry creates an asymmetry in output levels that raises the concentration in the market and thus, indirectly, creates market power. The aggregate profits increase as a result. For example, of the innovation reduces the marginal cost of the acquired firm to a point where its monopoly price equals the other firm's marginal cost (c), then the acquired firm has become a monopolist. 
If there is technological uncertainty, the alliance may be more profitable than the merger. This confirms the intuition that an alliance is a flexible instrument that firms use in uncertain environments. 


\section{REFERENCES}

Bondt, R. De and R. Veugelers (1991) Strategic Investment with Spillovers, European Journal of Political Economy, 7: 345-366.

D'Aspremont, C. and A. Jacquemin (1988) Cooperative and Noncooperative R\&D in Duopoly with Spillovers, American Economic Review, 78(5), Dec.: 1133-1137.

Martin, S. (1993) Advanced Industrial Economics, Oxford: Blackwell.

Salinger, M.A. (1988) Vertical Mergers and Market Foreclosure, Quarterly Journal of Economics, May: 345-356. 
Appendix A: The market contract

Proof of equations (9) to (11).

Cases 1 and 2. The manufacturing firms will use the innovator's technology if $\mathrm{T} 2$ does not arrive (case 1) or if, when it arrives, it is non-drastic (case 2). In both cases, the innovator faces an upper bound on its license fee: $1 \leq \mathrm{k}$, where $\mathrm{k}=\mathrm{x}$ in case 1 , and where $\mathrm{k}=\mathrm{x}+\mathrm{c}^{-}-\mathrm{c}$ in case 2 . The marginal cost is $c-x+1$, firms' output levels are $(a-(c-x+1)) / 3 b$, and the aggregate license revenue is $21(a-(c-x+1)) / 3 b$. The firm thus faces the maximization problem: choose a license fee $l$ that maximizes $21(\mathrm{a}-(\mathrm{c}-\mathrm{x}+\mathrm{l})) / 3 \mathrm{~b}$, subject to the constraint that $0 \leq 1 \leq \mathrm{k}$. Solving this problem with the Kuhn-Tucker conditions gives

(A.1) $\quad 1=$

$$
\mathrm{k}, \text { if } \mathrm{k} \leq(\mathrm{a}-\mathrm{c}+\mathrm{x}) / 2
$$

$$
(\mathrm{a}-\mathrm{c}+\mathrm{x}) / 2 \text {, if } \mathrm{k}>(\mathrm{a}-\mathrm{c}+\mathrm{x}) / 2 \text {. }
$$

Apply this solution to cases 1 and 2 .

Case 1. If $\mathrm{T} 2$ does not arrive, where $\mathrm{k}=\mathrm{x}$, then 1 equals $\mathrm{x}$, if $\mathrm{x} \leq(\mathrm{a}-\mathrm{c}+\mathrm{x}) / 2$, i.e., $\mathrm{x} \leq \mathrm{a}-\mathrm{c}$. Otherwise, 1 equals $(a-c+x) / 2$, if $x>a-c$. Note that, of course, $x<c$. If $2 c<a$, then it is impossible that $\mathrm{a}-\mathrm{c}<\mathrm{x}<\mathrm{c}$. Hence, for convenience we now only explore this particular case, which explains the salience of assumption (5). Hence,

(A.2) Licensing if no T2 arrives: $1=\mathrm{x}$, for all $0 \leq \mathrm{x}<\mathrm{c}$ (case 1 ).

The marginal costs are $c-x+x=c$, and the output levels are $(a-c) / 3 b$. The license revenue follows:

$$
\mathrm{L}=2 \mathrm{x}(\mathrm{a}-\mathrm{c}) / 3 \mathrm{~b}(\text { case } 1)
$$

Case 2. If $\mathrm{T} 2$ does arrive, and is non-drastic $\left(\mathrm{c}-\mathrm{x}<\mathrm{c}^{`}\right.$ or $\left.\mathrm{c}-\mathrm{c}^{`}<\mathrm{x}\right)$, then $k$ in equation (A.1) equals $\mathrm{x}+\mathrm{c}^{\prime}-\mathrm{c}$. It follows that

$$
\mathrm{x}+\mathrm{c}^{\prime}-\mathrm{c} \text {, if } \mathrm{k}=\mathrm{x}+\mathrm{c}^{\prime}-\mathrm{c} \leq(\mathrm{a}-\mathrm{c}+\mathrm{x}) / 2 \text {, that is, if } \mathrm{x} \leq \mathrm{a}-2 \mathrm{c}^{\prime}+\mathrm{c} \text {; and }
$$

$$
\begin{aligned}
& 1= \\
& (a-c+x) / 2, \text { if } a-2 c^{\prime}+c<x .
\end{aligned}
$$

Note that since $c^{\prime}<\mathrm{c}$ and $2 \mathrm{c}<\mathrm{a}$, it follows that $2 \mathrm{c}^{\prime}<\mathrm{a}$. Hence, it holds that $\mathrm{x}<\mathrm{c}<\mathrm{a}-2 \mathrm{c}^{\prime}+\mathrm{c}$. Thus, the case where $x>a-2 c^{\prime}+c$ does not emerge. It follows that

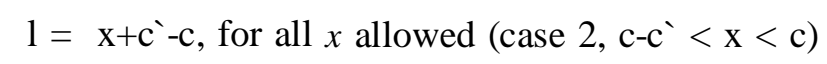

The marginal costs, $c-x+1$, are equal to $c^{\prime}$. Thus $c^{\prime}$ imposes a binding constraint on the license fee: the rival's technology has a real effect, even though neither firm chooses T2. Substitute this in 
equation (2) for the output levels. Thus,

(A.6) $\quad \mathrm{L}=2\left(\mathrm{x}+\mathrm{c}^{\prime}-\mathrm{c}\right)\left(\mathrm{a}-\mathrm{c}^{\prime}\right) / 3 \mathrm{~b}$, if $\mathrm{c}-\mathrm{c}^{\prime}<\mathrm{x}<\mathrm{c}$.

Case 3. If $\mathrm{T} 2$ arrives, and is drastic $\left(\mathrm{x} \leq \mathrm{c}-\mathrm{c}^{\prime}\right)$, then the license fee is zero, and marginal costs are $c^{\prime}$. The license revenues, L, are also zero. This concludes the proof. 
Appendix B: The market transaction, the first period of the game

In the first period, the innovator chooses the profit maximizing $R \& D$ effort, $x$, subject to the constraints $0 \leq \mathrm{x}<\mathrm{c}$. Straightforward but extremely tedious computations reveal that:

$$
\mathrm{x}_{\mathrm{c}}^{(1)}=2(1-\rho) \frac{a-c}{3 \gamma b}, \text { where } \mathrm{x} \leq \mathrm{c}-\mathrm{c}^{\prime} \text {, if } 0 \leq \mathrm{c}^{\prime} \leq \mathrm{c}_{\mathrm{c}}{ }_{\mathrm{c}} \text {; }
$$

$$
\begin{aligned}
& \mathrm{x}_{\mathrm{c}}^{*}= \\
& \mathrm{x}_{\mathrm{c}}^{(2)}=2 \frac{a-c+\rho\left(c-c^{\prime}\right)}{3 \gamma b} \text {, where } \mathrm{c}-\mathrm{c}^{\prime}<\mathrm{x}<\mathrm{c} \text {, if } \mathrm{c}_{\mathrm{c}}^{\prime}<\mathrm{c}^{\prime} \leq \mathrm{c} \text {. }
\end{aligned}
$$

The subscript $\mathrm{c}$ refers to the market contract. The asterisk refers to optimal outcomes. The threshold for $c^{\prime}, c_{c}^{\prime}$, equals $c-\frac{(2-\rho)(a-c)}{3 \gamma b-\rho}$. The two solutions for $\mathrm{x}$ are the interior optima for $\Pi^{1}$ and $\Pi^{2}$ in equation (12), respectively. It is intuitive that when $\rho=0$, the innovator's profit equals $2 x(a-c) / 3 b-(\gamma / 2) x^{2}$, and the profit maximizing $R \& D$ effort is $2(a-c) / 3 \gamma b$ (independent of $c^{\prime}$, of course). If $c^{\prime}$ falls below the threshold $\left(c_{c}^{\prime}\right)$, the innovator cuts back on its R\&D effort (from 2(a$\left.c+\rho\left(c-c^{\prime}\right)\right) / 3 \gamma b$ to $\left.2(1-\rho)(a-c) / 3 \gamma b\right)$, which is an intuitive result. ${ }^{7}$ Observe that for high $c^{\prime}\left(c^{\prime}{ }_{c}<c^{\prime}\right.$ $\leq \mathrm{c}$ ), a lower c'stimulates R1's R\&D effort: a kind of leapfrogging. Substitute equation (B.1) into equation (12) for the innovator's optimal expected profits at $t=0$ :

$$
\Pi_{\mathrm{c}}^{\mathrm{R} 1^{*}(1)}=2(1-\rho)^{2} \frac{(a-c)^{2}}{9 b^{2} \gamma}\left(\text { where } \mathrm{x}<\mathrm{c}-\mathrm{c}^{\prime}\right), \text { if } 0 \leq \mathrm{c}^{\prime}<\mathrm{c}_{\mathrm{c}}^{\prime} \text {; }
$$

$$
\begin{aligned}
& \Pi_{\mathrm{c}}^{\mathrm{R} 1^{*}}= \\
& \Pi_{\mathrm{c}}^{\mathrm{R} 1^{*}(2)}=\frac{2}{9 b^{2} \gamma}\left[a-c+\rho\left(c-c^{\prime}\right)\right]^{2}-2 \rho\left(c-c^{\prime}\right) \frac{a-c^{\prime}}{3 b}\left(\text { where } c^{-c^{\prime}}<\mathrm{x}<\mathrm{c}\right), \text { if } \mathrm{c}^{\prime}{ }_{\mathrm{c}} \leq \mathrm{c}^{\prime}<\mathrm{c} .
\end{aligned}
$$

It follows that $\partial \Pi_{R 1} / \partial c^{\prime}=0$, for small $c^{\prime}$, and $\partial \Pi_{R 1} / \partial c^{\prime}>0$, for large $c^{\prime}$. This is an intuitive result: for small enough $c^{\prime}$, the innovator exclusively banks on the possibility that $\mathrm{T} 2$ does not emerge at all. For larger c', the innovator will license its technology even if T2 emerges. Since c' now determines the size of the license fee, it influences the R\&D incentives. It is also obvious why $\partial \Pi_{\mathrm{R} 1} / \partial \rho<0$ for all $\mathrm{c}^{\prime}<\mathrm{c}$.

Due to equation (10), the aggregate output level by the manufacturing firms, Q, does not depend on the innovator's R\&D. With symmetric marginal costs, $\mathrm{c}_{1}$, the aggregate output level equals $Q=2\left(a-c_{1}\right) / 3 b$ (equation 3 ). In case 1 , this equals $2(a-c) / 3 b$, and in cases 2 and 3 , this equals $2\left(a-c^{`}\right) / 3 b$. Hence the expected aggregate output level at $t=0, Q_{c}{ }^{*}$, is:

7. Note that the associated marginal cost, $c-\mathrm{x}_{\mathrm{c}}{ }^{*}$, should be positive for all possible $\rho$ and all possible $c^{\prime}\left(\right.$ including $\left.c^{\prime}=0\right)$. Since $\left.x_{c}^{(2)} \leq 2\left(a-c+\left(c-c^{\prime}\right)\right) / 3 \gamma b=2\left(a-c^{\prime}\right)\right) / 3 \gamma b \leq 2 a / 3 \gamma b$, it holds that $c-x_{c}^{(2)} \geq c-2 a / 3 \gamma b$, and $c-2 a / 3 \gamma b \geq 0$ if $\gamma b>2 / 3 a / c$, which accounts for assumption (6). Hence, assumption (6) guarantees positive levels of marginal costs. 
(B.3) $\quad \mathrm{Q}_{\mathrm{c}}{ }^{*}=2\left[\mathrm{a}-\left(\rho \mathrm{c}^{\prime}+(1-\rho) \mathrm{c}\right)\right] / 3 \mathrm{~b}$.

The expected profits of firms 1 and $2, \Pi_{i}$, are $\rho\left(a-c^{\prime}\right)^{2} / 9 b+(1-\rho)(a-c)^{2} / 9 b$ (which follows from equations 4 and 10). Add their profits to $\Pi_{c}{ }^{R 1^{*}}$ in equation (B.2), to get the expected (at $\left.t=0\right)$ joint profit, $\Pi_{c}{ }^{{ }^{*}}$ :

(B.4) $\quad \Pi_{c}{ }^{* *}=2 \mathrm{~A} / 9 \mathrm{~b}$, where A equals:

$(1-\rho)^{2}(a-c)^{2} / \gamma b+2 \rho(a-c)\left(c-c^{\prime}\right)+\rho\left(c-c^{\prime}\right)^{2}+(a-c)^{2}$, where $x<c-c^{\prime}$, if $0 \leq c^{\prime}<c_{c}^{\prime} ;$

$\mathrm{A}=$

$\left(a-c+\rho\left(c-c^{\prime}\right)\right)^{2} / \gamma b-\rho(a-c)\left(c-c^{\prime}\right)-2 \rho\left(c-c^{\prime}\right)^{2}+(a-c)^{2}$, where $c-c^{\prime}<x<c$, if $c^{\prime}{ }_{c} \leq c^{\prime}<c$. 
Appendix C: The expected profit of the merged firm:

$$
\Pi^{(1)}=\rho\left(a-c^{\prime}\right)^{2} / 9 b+(1-\rho)\left[(a-c)^{2}+7(a-c) x+x^{2}\right] / 9 b-(\gamma / 2) x^{2} \text {, if } 0<x \leq c-c^{\prime}(\text { cases } 1 \text { and } 3) ;
$$

$$
\begin{aligned}
& \Pi_{1}= \\
& \Pi^{(2)}=\rho\left[(a-c)^{2}+7(a-c) x-5(a-c)\left(c-c^{\prime}\right)+x^{2}+5 x\left(c-c^{\prime}\right)-5\left(c-c^{\prime}\right)^{2}\right] / 9 b+(1-\rho)\left[(a-c)^{2}+7(a-c) x+x^{2}\right] / 9 b- \\
& (\gamma / 2) x^{2}, \text { if } c^{-} c^{\prime}<x \leq c(\text { cases } 1 \text { and } 2) .
\end{aligned}
$$

The two functions $\Pi^{(1)}$ and $\Pi^{(2)}$ are quadratic in the R\&D effort, $x$. The function $\Pi_{1}$ is continuous but not continuously differentiable (at $\left.\mathrm{x}=\mathrm{c}-\mathrm{c}^{\prime}\right)$. Choose the $\mathrm{R} \& \mathrm{D}$ levels that are the interior solution to $\Pi^{(1)}$ and $\Pi^{(2)}$ :

$$
\mathrm{x}_{\mathrm{m}}{ }^{*(1)}=\frac{7(1-\rho)(a-c)}{9 b \gamma-2+2 \rho} ; \text {, if } 0 \leq \mathrm{c}^{\prime}<\mathrm{c}_{\mathrm{m}}^{\prime} ; \text { and }
$$

$$
\begin{aligned}
& \mathrm{x}_{\mathrm{m}}{ }^{*}= \\
& \mathrm{x}_{\mathrm{m}}{ }^{*(2)}=\frac{7(a-c)+5 \rho\left(c-c^{\prime}\right)}{9 b \gamma-2}, \text { if } \mathrm{c}_{\mathrm{m}}{ }^{\prime}<c^{\prime} \leq \mathrm{c}^{8}
\end{aligned}
$$

The second order conditions hold for $-2+9 \gamma b>0$ and $-2+2 \rho+9 \gamma b>0$, which follow from $4 / 3<$ $\gamma b$. For low values of $c^{\prime}\left(0 \leq c^{\prime}<c_{m}^{\prime}\right)$, the merged firm chooses a small R\&D effort, such that 0 $<\mathrm{x} \leq \mathrm{c}-\mathrm{c}^{\prime}$ : if T2 comes, it is drastic, and replaces the innovation T1. If $\mathrm{c}^{\prime}$ is high $\left(\mathrm{c}_{\mathrm{m}}^{\prime}<\mathrm{c}^{\prime} \leq \mathrm{c}\right)$, the firm chooses a high $R \& D$ effort $\left(c^{-} c^{\prime}<x \leq c\right)$, such that if T2 comes neither firm uses it, but it does depress the license fee that the innovator may ask ( $c^{`}$ always imposes a binding constraint on $\left.1: 1=x+c^{\prime}-c\right)$. The optimal expected profit of the merged firm is:

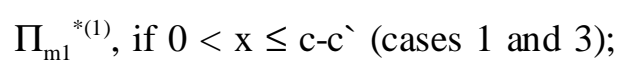

$$
\begin{aligned}
& \Pi_{\mathrm{m} 1}{ }^{*}= \\
& \Pi_{\mathrm{m} 1}{ }^{*}(2)
\end{aligned}
$$

where $\Pi_{\mathrm{m} 1}{ }^{*(\mathrm{i})}=\mathrm{A}^{(\mathrm{i})}(\mathrm{a}-\mathrm{c})^{2}+\mathrm{B}^{(\mathrm{i})}(\mathrm{a}-\mathrm{c})\left(\mathrm{c}-\mathrm{c}^{\prime}\right)+\mathrm{C}^{(\mathrm{i})}\left(\mathrm{c}-\mathrm{c}^{\prime}\right)^{2}$. It holds that

$$
\begin{aligned}
& \mathrm{A}^{(1)}=\frac{1}{18} \cdot \frac{\left(-y 4 \rho+4 y \rho^{2}+45+18 \cdot y \cdot \mathrm{b}\right)}{(\mathrm{b} \cdot(-2+2 \cdot \rho+9 \cdot \gamma \cdot \mathrm{b}))} \\
& \mathrm{B}^{(1)}=\frac{2}{9} \cdot \frac{\rho}{\mathrm{b}} \\
& \mathrm{C}^{(1)}=\frac{1}{9} \cdot \frac{\rho}{\mathrm{b}}
\end{aligned}
$$

8. The threshold value for $\mathrm{c}^{\prime}, \mathrm{c}_{\mathrm{m}}^{\prime}$, is a root of $\Pi^{(2)^{*}}-\Pi^{(1)^{*}}=0$ (there is another root that exceeds $a$ ). This root is an expression too long to be reproduced here. In the special case where $\rho=0, c_{\mathrm{m}}{ }^{\prime}=$ $(9 \gamma b c+5 c-7 a) /(9 \gamma b-2)$. 


$$
\begin{aligned}
& \mathrm{A}^{(2)}=\frac{1}{2} \cdot \frac{(2 \cdot y \cdot b+5)}{(\mathrm{b} \cdot(\cdot 2+9 \cdot \gamma \cdot b))} \\
& \mathrm{B}^{(2)}=-5 \cdot \rho \frac{(y \cdot b-1)}{(b \cdot(-2+9 \cdot \gamma \cdot b))} \\
& \mathrm{C}^{(2)}=-\frac{5}{18} \cdot \rho \frac{(18 \cdot y \cdot b-4-5 \cdot \rho)}{(b \cdot(-2+9 \cdot \gamma b))}
\end{aligned}
$$

The aggregate industry output equals:

$$
\left.\mathrm{Q}_{\mathrm{m}}{ }^{*(1)}=\rho 2 \frac{a-c^{\prime}}{3 b}+(1-\rho) \frac{2(a-c)+x}{3 b} \text {, if } 0 \leq \mathrm{c}^{\prime}<\mathrm{c}_{\mathrm{m}}^{\prime} \text { (cases } 1 \text { and } 3\right) \text {; and }
$$

(C.4) $\quad \mathrm{Q}_{\mathrm{m}}{ }^{*}=$

$$
\mathrm{Q}_{\mathrm{m}}{ }^{*(2)}=\rho \frac{2 a-c-c^{\prime}+x}{3 b}+(1-\rho) \frac{2(a-c)+x}{3 b} \text {, if } \mathrm{c}_{\mathrm{m}}^{\prime}<\mathrm{c}^{\prime} \leq \mathrm{c}(\text { cases } 1 \text { and } 2) \text {. }
$$

Substitute the R\&D levels for the optimal aggregate expected output level, $\mathrm{Q}_{\mathrm{m}}{ }^{*}$ :

$$
\mathrm{Q}_{\mathrm{m}}{ }^{*(1)} \text {, if } 0 \leq \mathrm{c}^{\prime}<\mathrm{c}_{\mathrm{m}}^{\prime} \text {; and }
$$

$$
\begin{aligned}
& \mathrm{Q}_{\mathrm{m}}{ }^{*}= \\
& \mathrm{Q}_{\mathrm{m}}{ }^{*}{ }^{(2)}, \text { if } \mathrm{c}_{\mathrm{m}}{ }_{\mathrm{m}}<\mathrm{c}^{\prime} \leq \mathrm{c} ;
\end{aligned}
$$

where $\mathrm{Q}_{\mathrm{m}}{ }^{*(\mathrm{i})}=\mathrm{A}^{(\mathrm{i})}(\mathrm{a}-\mathrm{c})+\mathrm{B}^{(\mathrm{i})}\left(\mathrm{c}-\mathrm{c}^{\prime}\right)$. It holds that:

$$
\begin{aligned}
& \mathrm{A}^{(1)}=\frac{1}{3} \frac{\left(7 \cdot p^{2}-10 \cdot \beta+3+18 \cdot y \cdot \mathrm{b}\right)}{((-2+2 \cdot p+9 \cdot 7 \cdot \mathrm{b}) \cdot \mathrm{b})} \\
& \mathrm{B}^{(1)}=\frac{2}{3} \frac{\rho}{\mathrm{b}}
\end{aligned}
$$

$$
A^{(2)}=\frac{(1+6 \cdot y b)}{(-2+9 \cdot y \cdot h) \cdot h}
$$

$$
\mathrm{B}^{(2)}=\cdot \frac{(1+3 \cdot y \cdot h)}{(-2+y \cdot y \cdot b) \cdot b}
$$

The expected profit (at $\mathrm{t}=0$ ) of firm 2 is:$$
\Pi_{2}^{*(1)}=\rho \frac{\left(a-c^{\prime}\right)^{2}}{9 b}+(1-\rho) \frac{(a-c-x)^{2}}{9 b} \text {, if } 0 \leq c^{\prime}<c^{\prime}{ }_{m} \text { (cases } 1 \text { and 3); and }
$$

(C.6) $\quad \Pi_{2}{ }^{*}=$

$$
\left.\Pi_{2}{ }^{*(2)}=\rho \frac{\left(a+c-2 c^{`}-x\right)^{2}}{9 b}+(1-\rho) \frac{(a-c-x)^{2}}{9 b} \text {, if } c^{\prime}{ }_{m}<c^{\prime} \leq c \text { (cases } 1 \text { and } 2\right) \text {. }
$$

Substitute the optimal R\&D levels in equation (C.6), and add the result to the profit of the merged 
firm, in equation (C.3) for the expected joint profit of the three firms:

(C.7)

$$
\Pi_{\mathrm{m}}^{\mathrm{J}^{*(1)}} \text {, if } 0 \leq \mathrm{c}^{\prime}<\mathrm{c}_{\mathrm{m}}^{\prime} \text {; and }
$$

$$
\begin{aligned}
& \Pi_{\mathrm{m}}^{\mathrm{J}^{*}}= \\
& \Pi_{\mathrm{m}}^{\mathrm{J}^{*}(2)}, \text { if } \mathrm{c}_{\mathrm{m}}{ }^{\prime}<\mathrm{c}^{\prime} \leq \mathrm{c} ;
\end{aligned}
$$

where $\Pi_{\mathrm{m}}{ }^{{ }^{*}(\mathrm{i})}=\mathrm{A}^{(\mathrm{i})}(\mathrm{a}-\mathrm{c})^{2}+\mathrm{B}^{(\mathrm{i})}(\mathrm{a}-\mathrm{c})\left(\mathrm{c}-\mathrm{c}^{\prime}\right)+\mathrm{C}^{(\mathrm{i})}\left(\mathrm{c}-\mathrm{c}^{\prime}\right)^{2}$. It holds that

$$
\begin{aligned}
& \mathrm{A}^{(1)}=\frac{1}{18} \frac{-94 \rho+49 \rho^{2}+45+18 \gamma b}{b(-2+2 \rho+9 \gamma b)}+\frac{\rho}{9 b}+\frac{9(1-\rho)(-1+\rho+\gamma b)^{2}}{b(-2+2 \rho+9 \gamma b)^{2}} \\
& \mathrm{~B}^{(1)}=\frac{4}{9} \cdot \frac{\rho}{\mathrm{b}} \\
& \mathrm{C}^{(1)}=\frac{2}{9} \cdot \rho \cdot \frac{1}{\mathrm{~b}} \\
& \mathrm{~A}^{(2)}=\frac{1}{2} \cdot \frac{\left(5 \cdot \gamma b+36 \cdot \gamma^{2} \cdot b^{2}+8\right)}{\left[b(2,9 \cdot \gamma b)^{2} \mid\right.} \\
& B^{(2)}=. \nu(\cdot 1+y b) \frac{(8+9 \cdot y b)}{\left.\mid b \cdot(-2+9 y b)^{2}\right\rceil}
\end{aligned}
$$

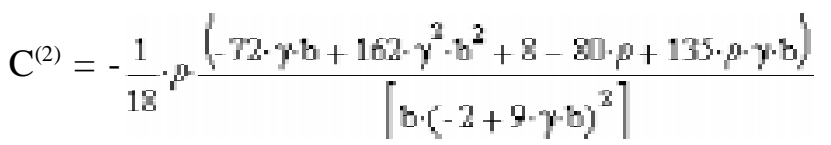


Appendix D: the alliance.

The (interior) optima for $x$ from equation (31) are:

(D.1)

$$
\mathrm{x}_{\mathrm{a}}^{*(1)}=\frac{4(1-\rho)(a-c)}{9 \gamma b-4+4 \rho} \text {, if } 0 \leq \mathrm{c}^{\prime} \leq \mathrm{c}_{\mathrm{a}}^{\prime}\left(\text { where } 0 \leq \mathrm{x} \leq \mathrm{c}-\mathrm{c}^{\prime}\right) \text {; and }
$$

$$
\begin{aligned}
& \mathrm{x}_{\mathrm{a}}{ }^{*}= \\
& \mathrm{x}_{\mathrm{a}}{ }^{*(2)}=\frac{4(a-c)}{9 \gamma b-4}, \text { if } \mathrm{c}_{\mathrm{a}}^{\prime}<\mathrm{c}^{\prime} \leq \mathrm{c}\left(\text { where } \mathrm{c}^{-} \mathrm{c}^{\prime}<\mathrm{x} \leq \mathrm{c}\right) .
\end{aligned}
$$

Some tedious computations show that $c^{\prime}{ }_{a}=a-9 \gamma b(a-c) /[\sqrt{ }(9 \gamma b-4) \sqrt{ }(9 \gamma b-4+4 \rho)]$. For $\rho=0$, the optimal R\&D level coincides with $\mathrm{x}_{\mathrm{a}}{ }^{*}$, , which obviously maximizes the associated profit in equation (31) when $\rho=0$. The second order condition holds if $-4+4 \rho+9 \gamma b>0$ and $-4+9 \gamma b>0$, which follows from $\rho>0$ and $4 / 3<\gamma b$. Substitute (D.1) in equation (31) for the optimal, expected, aggregate profit of the alliance:

$$
\Pi_{\mathrm{a}}^{\mathrm{J}^{*}(1)} \text {, if } 0 \leq \mathrm{c}^{\prime}<\mathrm{c}_{\mathrm{m}}^{\prime} \text {; and }
$$

$$
\begin{aligned}
& \Pi_{\mathrm{a}}^{\mathrm{J}^{*}}= \\
& \Pi_{\mathrm{a}}^{\mathrm{J}^{*}(2)}, \text { if } \mathrm{c}_{\mathrm{m}}^{\prime}<\mathrm{c}^{\prime} \leq \mathrm{c} ;
\end{aligned}
$$

where $\Pi_{\mathrm{a}}^{\mathrm{J}^{*}(\mathrm{i})}=\mathrm{A}^{(\mathrm{i})}(\mathrm{a}-\mathrm{c})^{2}+\mathrm{B}^{(\mathrm{i})}(\mathrm{a}-\mathrm{c})\left(\mathrm{c}-\mathrm{c}^{-}\right)+\mathrm{C}^{(\mathrm{i})}\left(\mathrm{c}-\mathrm{c}^{\prime}\right)^{2}$. It holds that

$$
\begin{aligned}
& \mathrm{A}^{(1)}=\frac{2}{9} \cdot \frac{\left(y \cdot y \cdot b-4 \cdot \rho+4 \cdot \rho^{2}\right)}{(b \cdot(-4+4 \cdot \rho+9 \cdot \gamma \cdot b))} \\
& \mathrm{B}^{(1)}=\frac{4}{9} \frac{\rho}{\mathrm{b}} \\
& \mathrm{C}^{(1)}=\frac{2}{9} \cdot \rho \frac{1}{\mathrm{~b}}
\end{aligned}
$$

$$
\mathrm{A}^{(2)}=2 \cdot y \frac{1}{(\cdot 4+9 \cdot y \cdot b)}
$$

$\mathrm{B}^{(2)}=0$; and $\mathrm{C}^{(2)}=0$.

To compute the aggregate output level, observe from equation (29) that $\mathrm{c}_{1}=\mathrm{c}_{2}$. The output levels are $\left(a-c_{1}\right) / 3 b$ (equation 2), and the aggregate output level, $Q$, is $2\left(a-c_{1}\right) / 3 b$. Due to equation (29), $Q$ equals $2(a-c+x) / 3 b$ in cases 1 and 2 , and $2\left(a-c^{\prime}\right) / 3 b$, in case 3 . The size of the R\&D effort, which in turn depends on c', determines whether case 2 or 3 occurs if T2 arrives. That is,

$$
\mathrm{Q}_{\mathrm{a}}^{*(1)}=\rho 2 \frac{a-c^{\prime}}{3 b}+(1-\rho) 2 \frac{a-c+x}{3 b} \text {, where } \mathrm{x}=\frac{4(1-\rho)(a-c)}{9 \gamma b-4+4 \rho} \text {, if } 0 \leq \mathrm{c}^{\prime} \leq \mathrm{c}^{\prime}{ }_{\mathrm{a}} \text { (where } 0 \leq \mathrm{x}
$$


$\left.\leq \mathrm{c}^{\prime} \mathrm{c}^{\prime}\right)$; and
(D.3) $\mathrm{Q}_{\mathrm{a}}{ }^{*}=$
$\mathrm{Q}_{\mathrm{a}}{ }^{*(2)}=2 \frac{a-c+x}{3 b}$, where $\mathrm{x}=\frac{4(a-c)}{9 \gamma b-4}$, if $^{\mathrm{c}^{\prime}}{ }_{\mathrm{a}}<\mathrm{c}^{\prime} \leq \mathrm{c}\left(\right.$ where $\left.\mathrm{c}^{-} \mathrm{c}^{\prime}<\mathrm{x} \leq \mathrm{c}\right)$.

The expected aggregate output level is:

(D.4) $\quad \mathrm{Q}_{\mathrm{a}}{ }^{*}=$

$\mathrm{Q}_{\mathrm{a}}{ }^{*(1)}=\mathrm{A}(\mathrm{a}-\mathrm{c})+\mathrm{B}\left(\mathrm{c}-\mathrm{c}^{\prime}\right)$, if $0 \leq \mathrm{c}^{\prime} \leq \mathrm{c}^{\prime}{ }_{\mathrm{a}}$, and

$$
\mathrm{Q}_{\mathrm{a}}^{*(2)}=\frac{6 \gamma(a-c)}{9 \gamma b-4} \text {, if } \mathrm{c}_{\mathrm{a}}^{\prime}<\mathrm{c}^{\prime} \leq \mathrm{c} \text {; }
$$

where

$$
\begin{aligned}
& \mathrm{A}=\frac{2}{3} \cdot \frac{\left(-4 \cdot \rho+4 \rho^{2}+9 \cdot \gamma \cdot \mathrm{b}\right)}{(-4+4 \rho+9 \cdot y \cdot b) \cdot b} \\
& \mathrm{~B}=\frac{2}{3} \cdot \rho \frac{1}{\mathrm{~b}}
\end{aligned}
$$


Appendix E: Comparing the market, the merger and the alliance

In the first period, the levels of $x$ chosen depend on critical values of $c^{\prime}$, called $c^{\prime}{ }_{c}$ in the market), $\mathrm{c}_{\mathrm{m}}{ }_{\mathrm{m}}$ (in the merger), and $\mathrm{c}_{\mathrm{a}}{ }_{\mathrm{a}}$ (alliance). Numerical simulations show for relevant parameters $\mathrm{a}, \mathrm{b}, \mathrm{c}$, and $\gamma$ (where equations $5-7$ hold) and for $\rho$ from 0 to 1 , that $0<\mathrm{c}_{\mathrm{m}}<\mathrm{c}_{\mathrm{c}_{\mathrm{c}}}<\mathrm{c}_{\mathrm{a}}^{\prime}<\mathrm{c}$. In the special case where $\rho$ equals zero, the threshold values for $c^{\prime}$ are such that:

(E.1) $\mathrm{c}-\mathrm{c}_{\mathrm{a}}^{\prime}=4(\mathrm{a}-\mathrm{c}) /(9 \gamma \mathrm{b}-4)$;

(E.2) $\mathrm{c}_{\mathrm{a}}{ }_{\mathrm{a}}-\mathrm{c}_{\mathrm{c}}{ }_{\mathrm{c}}=2 / 3(\mathrm{a}-\mathrm{c})(3 \gamma \mathrm{b}-4) /((9 \gamma \mathrm{b}-4) \gamma \mathrm{b})$

(E.3) $\mathrm{c}_{\mathrm{c}}{ }_{\mathrm{c}}-\mathrm{c}_{\mathrm{m}}{ }=1 / 3(\mathrm{a}-\mathrm{c})(3 \gamma \mathrm{b}+4) /((9 \gamma \mathrm{b}-2) \gamma \mathrm{b})$

(E.4) $\mathrm{c}_{\mathrm{m}}{ }^{-}-0=(9 \gamma b c+5 c-7 a) /(9 \gamma b-2)$

These expressions are all positive, which confirms for $\rho=0$ that $0<\mathrm{c}_{\mathrm{m}}^{\prime}<\mathrm{c}_{{ }_{\mathrm{c}}}<\mathrm{c}^{\prime}{ }_{\mathrm{a}}<\mathrm{c}$. This gives four intervals for comparing the first period outcomes: the interval $\left[0, c_{m}^{\prime}{ }_{m}\right],\left[c_{m}^{\prime}, c_{c}^{\prime}\right],\left[c_{c}^{\prime}, c_{a}^{\prime}\right]$, and $\left[c^{\prime}{ }_{a}, c\right]$. 
Appendix F: Comparing the R\&D levels

Interval 1: $0<\mathrm{c}^{\prime} \leq \mathrm{c}_{\mathrm{m}}{ }_{\mathrm{m}}$. The $\mathrm{R} \& \mathrm{D}$ effort levels chosen are in the top rows of equations B.1, C.2 and D.1. Computations show that:

$(F .1) x a-x c=\frac{2}{3} \cdot(\rho-1) \cdot(a-c) \cdot \frac{(3 \cdot \gamma \cdot b-4+4 \cdot \rho)}{((-4+4 \cdot \rho+9 \cdot \gamma \cdot b) \cdot(\gamma \cdot b))}$

This expression is negative as $\rho<1$, a-c $>0,3 \gamma b-4+4 \rho \geq 3 \gamma b-4>0$, due to equation (6). Equation (6) also implies that $9 \gamma b-4+4 \rho \geq 9 \gamma b-4>0$. Hence, $x_{a}<x_{c}$ (and equality if $\rho=1$ ).

$(F .2) x m-x c=\frac{-1}{3} \cdot(\rho-1) \cdot(a-c) \cdot \frac{(3 \cdot \gamma \cdot b+4-4 \cdot \rho)}{((-2+2 \cdot \rho+9 \cdot \gamma \cdot b) \cdot(\gamma \cdot b))}$

This expression is positive as $\rho<1$ and $9 \gamma b-2+2 \rho \geq 9 \gamma b-2>0$. Hence, $x_{c}<x_{m}$ and equality if $\rho$ = 1. Conclusion: $\mathrm{x}_{\mathrm{a}} \leq \mathrm{x}_{\mathrm{c}} \leq \mathrm{x}_{\mathrm{m}}$.

Interval 2: $\mathrm{c}_{\mathrm{m}}{ }_{\mathrm{m}}<\mathrm{c}^{\prime} \leq \mathrm{c}_{\mathrm{c}}{ }_{\mathrm{c}}$. The R\&D effort levels chosen are in the top row of equation (13), the bottom row of equation (22), and the top row of equation (32). The formulas for $x_{c}$ and $x_{a}$ do not change, and it immediately follows that still $\mathrm{x}_{\mathrm{a}}<\mathrm{x}_{\mathrm{c}}$. The result for the merger is:

(F.3) $x \mathrm{xm}-\mathrm{xc}=\frac{1}{3} \cdot \frac{(3 \cdot \gamma \cdot \mathrm{b} \cdot \rho \cdot \mathrm{ac}+15 \cdot \gamma \cdot \mathrm{b} \cdot \rho \cdot \mathrm{ac} 2+3 \cdot \gamma \cdot \mathrm{b} \cdot \mathrm{ac}+4 \cdot \mathrm{ac}-4 \cdot \rho \cdot \mathrm{ac})}{((-2+9 \cdot \gamma \cdot \mathrm{b}) \cdot(\gamma \cdot \mathrm{b}))}$

Here, ac stands for a-c and $a c 2$ stands for a-c'. This expression is positive, hence, $\mathrm{x}_{\mathrm{c}}<\mathrm{x}_{\mathrm{m}}$. Conclusion: $\mathrm{x}_{\mathrm{a}}<\mathrm{x}_{\mathrm{c}}<\mathrm{x}_{\mathrm{m}}$.

Interval 3: $\mathrm{c}_{\mathrm{c}}^{\prime}<\mathrm{c}^{\prime} \leq \mathrm{c}_{\mathrm{a}^{\prime}}$.

The appropriate formulas for $x$ are in the bottom rows of equation B.1 and C.2 and in the top row of equation D.1:

(F.4) $x m-x c=\frac{-1}{3} \cdot \frac{(3 \cdot \rho \cdot d c \cdot \gamma \cdot b-3 \cdot \gamma \cdot b \cdot a c-4 \cdot a c-4 \cdot \rho \cdot d c)}{(-2+9 \cdot \gamma \cdot b) \cdot \gamma \cdot b}$

Read: $a c=a-c$ and dc $=c-c^{\prime}$. The expression is positive as ac- $\rho d c \geq a c-d c=a-2 c+c^{\prime} \geq a-2 c>0$.

(F.5) $x c-x a=\frac{2}{3} \cdot \frac{(-4+4 \cdot \rho+3 \cdot \gamma \cdot b+6 \cdot \gamma \cdot b \cdot \rho)}{\gamma \cdot b \cdot(-4+4 \cdot \rho+9 \cdot \gamma \cdot b)} \cdot a c+\frac{2}{3} \cdot \rho \cdot \frac{d c}{\gamma \cdot b}$

The expression is positive as $3 \gamma \mathrm{b}-4>0$ and $\mathrm{dc}>0$. Conclusion: again $\mathrm{x}_{\mathrm{a}}<\mathrm{x}_{\mathrm{c}}<\mathrm{x}_{\mathrm{m}}$.

Interval 4: $c^{\prime}{ }_{\mathrm{a}}<\mathrm{c}^{\prime} \leq \mathrm{c}$. 
The appropriate formulas for $x$ are in the bottom row in the equations B.1, C.2 and D.1. The formulas for $\mathrm{x}_{\mathrm{m}}$ and $\mathrm{x}_{\mathrm{c}}$ are the same as in interval 3, hence its conclusion applies here as well.

(F.6) $x c-x a=\frac{2}{3} \cdot \frac{(-4 \cdot a c+3 \cdot \gamma \cdot b \cdot a c-4 \cdot \rho \cdot d c+9 \cdot \rho \cdot d c \cdot \gamma \cdot b)}{\gamma \cdot b \cdot(-4+9 \cdot \gamma \cdot b)}$

This expression is positive as $3 \gamma b-4>0$ and $9 \gamma b-4>0$. Hence, $x_{a}<x_{c}$. The conclusion remains: $\mathrm{x}_{\mathrm{a}}<\mathrm{x}_{\mathrm{c}}<\mathrm{x}_{\mathrm{m}}$. To sum up: the four cases show $\mathrm{x}_{\mathrm{a}} \leq \mathrm{x}_{\mathrm{c}} \leq \mathrm{x}_{\mathrm{m}}$ and $\mathrm{x}_{\mathrm{a}}<\mathrm{x}_{\mathrm{c}}<\mathrm{x}_{\mathrm{m}}$ if $\rho<1$. QED 
Appendix G: Comparing the aggregate output levels

I give the analytical results for the special case where $\rho=0$, and simulation outcomes for $\rho>0$. The same intervals on $c^{\prime}$ exist as in appendix F. In comparing the aggregate output levels, note that $Q_{c}$ from equation (B.3) holds for all intervals. As for the merger, $Q_{m}{ }^{*}(1)$ holds in interval 1 and $\mathrm{Q}_{\mathrm{m}}{ }^{*(2)}$ holds in intervals 2, 3 and 4 (see equation C.5). As for the alliance, $\mathrm{Q}_{\mathrm{a}}{ }^{*(1)}$ holds in intervals 1,2 and 3, and $\mathrm{Q}_{\mathrm{a}}{ }^{*(2)}$ holds in interval 4 (see equation D.4).

Interval 1: $0<\mathrm{c}^{\prime} \leq \mathrm{c}_{\mathrm{m}}{ }_{\mathrm{m}}$. Compare $\mathrm{Q}_{\mathrm{c}}{ }^{*}, \mathrm{Q}_{\mathrm{m}}{ }^{*(1)}$ and $\mathrm{Q}_{\mathrm{a}}{ }^{*(1)}$. It holds that:

$$
\left(\mathrm{Q}_{\mathrm{a}}\right)^{(1)}-\left(\mathrm{Q}_{\mathrm{m}}\right)^{(1)}=\mathrm{ac} \cdot(-1+\rho)^{2} \cdot \frac{-4 \cdot \rho+3 \cdot \gamma \cdot \mathrm{b}+4}{(-4+4 \cdot \rho+9 \cdot \gamma \cdot \mathrm{b}) \cdot \mathrm{b} \cdot(-2+2 \cdot \rho+9 \cdot \gamma \cdot \mathrm{b})}
$$

and

$$
\left(\mathrm{Q}_{\mathrm{m}}\right)^{(1)}-\mathrm{Q}_{\mathrm{c}}=\frac{7}{3} \cdot(-1+\rho)^{2} \cdot \frac{\mathrm{ac}}{(-2+2 \cdot \rho+9 \cdot \gamma \cdot \mathrm{b}) \cdot \mathrm{b}} .
$$

Both expressions are positive.

Interval 2: $\mathrm{c}_{\mathrm{m}}{ }^{\prime}<\mathrm{c}^{\prime} \leq \mathrm{c}_{\mathrm{c}^{\prime}}$. Compare $\mathrm{Q}_{\mathrm{c}}{ }^{*}, \mathrm{Q}_{\mathrm{m}}{ }^{*(2)}$ and $\mathrm{Q}_{\mathrm{a}}{ }^{*}{ }^{1(1)}$. For the special case where $\rho=0$, it holds that:

$$
\left(\mathrm{Q}_{\mathrm{a}}\right)^{(1)}-\left(\mathrm{Q}_{\mathrm{m}}\right)^{(2)}=(3 \cdot \gamma \cdot \mathrm{b}+4) \cdot \frac{\mathrm{ac}}{(-4+9 \cdot \gamma \cdot \mathrm{b}) \cdot \mathrm{b} \cdot(-2+9 \cdot \gamma \cdot \mathrm{b})}
$$

This is positive, hence $\mathrm{Q}_{\mathrm{a}}{ }^{*(1)}>\mathrm{Q}_{\mathrm{m}}{ }^{*}(2)$. Simulations for $\rho=1$ show that the opposite holds. Cases do exist, therefore, where a merger entails a larger aggregate output level than the alliance.

Interval 3: $\mathrm{c}_{\mathrm{c}}^{\prime}<\mathrm{c}^{\prime} \leq \mathrm{c}_{\mathrm{a}^{\prime}}$.

Compare $\mathrm{Q}_{\mathrm{c}}{ }^{*}, \mathrm{Q}_{\mathrm{m}}{ }^{*(2)}$ and $\mathrm{Q}_{\mathrm{a}}{ }^{*}(1)$. The same results apply as in the previous interval.

Interval 4: $\mathrm{c}_{\mathrm{a}}^{\prime}<\mathrm{c}^{\prime} \leq \mathrm{c}$.

The special case where $\rho=0$ has the outcome:

$$
\left(Q_{a}\right)^{2}-\left(Q_{m}\right)^{2}=\frac{(3 \cdot \gamma \cdot b+4)}{((-4+9 \cdot \gamma \cdot b) \cdot((-2+9 \cdot \gamma \cdot b) \cdot b))} \cdot a c
$$

This is positive, hence $\mathrm{Q}_{\mathrm{a}}{ }^{*(2)}>\mathrm{Q}_{\mathrm{m}}{ }^{*(2)}$. If $\rho$ exceeds zero, simulations show cases where the opposite holds.

Intervals 2, 3 and $4: c_{\mathrm{m}}^{\prime}<\mathrm{c}^{\prime} \leq \mathrm{c}$.

Compute for these three intervals, for the special case where $\rho=0$, the difference: 
(G.5) $\quad\left(Q_{m}\right)^{2}-Q_{c}=\frac{7}{(3 \cdot((-2+9 \cdot \gamma \cdot b) \cdot b))} \cdot a c$

This is positive. Simulations show cases where the same holds for $\rho>0$. For the special case where $\rho=0$, this concludes the proof. $Q E D$ 
Appendix H: Joint profit levels

Due to the complicated expressions if $\rho$ is positive, I focus here on the case when $\rho=0$, i.e., where we ignore $\mathrm{T} 2$.

$$
\left(\pi_{\mathrm{m}}\right)^{\mathrm{J}}-\left(\pi_{\mathrm{a}}\right)^{\mathrm{J}}=\frac{1}{2} \cdot \mathrm{ac}^{2} \cdot(3 \cdot \gamma \cdot \mathrm{b}+4) \cdot \frac{(15 \cdot \gamma \cdot \mathrm{b}-8)}{\mathrm{b} \cdot(-2+9 \cdot \gamma \cdot \mathrm{b})^{2} \cdot(-4+9 \cdot \gamma \cdot \mathrm{b})}
$$

This expression is positive (as follows from equations 5 and 6 ).

$$
\left(\pi_{c}\right)^{J}-\left(\pi_{a}\right)^{J}=\frac{2}{9} \cdot a^{2} \cdot \frac{(5 \cdot \gamma \cdot b-4)}{\gamma \cdot b^{2} \cdot(-4+9 \cdot \gamma \cdot b)}
$$

This expression is positive.

$$
\left(\pi_{m}\right)^{J}-\left(\pi_{c}\right)^{J}=\frac{-1}{18} \cdot a c^{2} \cdot \frac{\left(-200 \gamma \cdot b+135 \gamma^{2} \cdot b^{2}+16\right)}{b^{2} \cdot(-2+9 \cdot \gamma \cdot b)^{2} \cdot \gamma}
$$

This function has the opposite sign of $S(\gamma b)$, where $S(x)=-200 x+135 x^{2}+16$. The roots of $S(x)=0$ are $x=20 / 27-(28 / 135) \sqrt{ } 10)(\approx 0.08)$ and $x=20 / 27+(28 / 135) \sqrt{ } 10(\approx 1.397) . S(x)$ is negative in between the roots and positive elsewhere. Hence, if $1.397<\gamma b$, then $S(\gamma b)$ is positive, and the expression in (H.3) is negative: the market contract is more profitable than the merger. $Q E D$

If $\rho$ is positive, the same four intervals have to be studied as in appendices F and G. I focus now on the merger and the alliance. Results are as follows.

Interval 1: $0<\mathrm{c}^{\prime} \leq \mathrm{c}_{\mathrm{m}}{ }_{\mathrm{m}}$. Compare $\Pi_{\mathrm{m}}{ }^{\mathrm{J}^{*}(1)}$ and $\Pi_{\mathrm{a}}^{\mathrm{J}^{*}(1)}$. It holds that:

$$
\Pi_{\mathrm{m}}{ }^{*(1)}-\Pi_{\mathrm{a}}{ }^{*(1)}=\frac{1}{2}-\mathrm{ac}^{2} \cdot(\beta-1)^{2} \cdot(8 \cdot p-8+15 \cdot y \cdot b) \frac{(-4 \cdot \beta+4+3-\gamma b)}{b-(-2+2 \cdot \beta+9 \cdot \gamma b)^{2} \cdot(-4+4 \cdot p+9 \cdot \gamma \cdot b)}
$$

This expression is positive for all $\rho<1$, and zero for $\rho=1$. If T2 comes with certainty, it is a drastic innovation both in the case of the merger (as $c^{\prime} \leq c_{m}^{\prime}$ ) and in the alliance (as $c^{\prime} \leq c_{m}<$ $\left.c^{\prime}{ }_{a}\right)$. In that case, neither the merger nor the alliance have an effect, and their $R \& D$ levels will equal zero (see equations C.2 and D.1).

Intervals 2 and 3 : $\mathrm{c}_{\mathrm{m}}^{\prime} \leq \mathrm{c}^{\prime} \leq \mathrm{c}_{\mathrm{a}}{ }_{\mathrm{a}}$. Simulate $\Pi_{\mathrm{m}}^{\mathrm{J}^{*}(2)}-\Pi_{\mathrm{a}}^{\mathrm{J}^{*}(1)} \cdot \Pi_{\mathrm{m}}^{\mathrm{J}^{*}(2)}-\Pi_{\mathrm{a}}^{\mathrm{J}^{*}(1)}$ is a function of the parameters $a, b, c, \gamma, \rho$, and, for convenience of notation, $d c\left(=c-c^{\prime}\right)$ rather than $c^{\prime}$. Note that

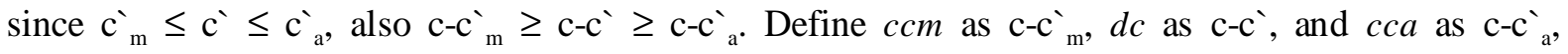
with $c c a \leq d c \leq c c m$. Both $c c a$ and $c c m$ are functions of the parameters $a, b, c, \gamma$, and $\rho$ (for $c_{a}^{\prime}$, see equation D.1).

Table 1 presents some simulation results (each row only records changes relative to the previous row). It is assumed that $\mathrm{a}=1, \mathrm{~b}=1$, and $\mathrm{c}=0.3$. These results show that cases do exist where the alliance is more profitable than the merger. These are cases where there is some probability (or certainty) that $\mathrm{T} 2$ arrives in the market. Moreover, $\gamma$ should not be too large, for 
then the sign of $\Pi_{\mathrm{m}}^{\mathrm{J} *(2)}-\Pi_{\mathrm{a}}^{\mathrm{J} *(1)}$ becomes negative. Also, dc should be 'small', that is, c' should be 'large' ( with in the interval $\mathrm{c}_{\mathrm{m}}^{\prime} \leq \mathrm{c}^{\prime} \leq$ $\left.c^{\prime}{ }_{a}\right)$. So if there is ( p r o b a b l e ) technological rivalry, the costs of R\&D are not too high, and the rival technology's marginal costs are not too low, then an alliance can be more profitable for the three firms jointly.

Note that if $\rho=1$, T2 comes with certainty, and is drastic for the alliance (as c'< $c^{\prime}$ ), such that the

\begin{tabular}{||l|l|l|l|l||}
\hline$\gamma$ & $\rho$ & $\mathrm{cca}$ & $\mathrm{ccm}$ & $\operatorname{Sign}$ of $\Pi_{\mathrm{m}}{ }^{\mathrm{J}(2)}-\Pi_{\mathrm{a}}^{\mathrm{J} *(1)}$ \\
\hline 2.9 & 0.9 & .067 & .121 & - \\
\hline & 0.7 & .079 & .139 & - \\
\hline & .5 & .092 & .158 & $\begin{array}{l}+(\mathrm{dc}=.1) \\
-(\mathrm{dc}=.15)\end{array}$ \\
\hline 3.3 & .9 & .058 & .104 & - \\
\hline 3.5 & & .054 & .097 & - \\
\hline 3.9 & & .048 & .086 & $\begin{array}{l}+(\mathrm{dc}=.05) \\
-(\mathrm{dc}=.075)\end{array}$ \\
\hline 4.3 & & .043 & .077 & - \\
\hline 9.9 & & .018 & .032 & - \\
\hline & .5 & .024 & .043 & - \\
\hline 4.9 & & .051 & 0.89 & $\begin{array}{l}+(\mathrm{dc}=.06) \\
-(\mathrm{dc}=.075)\end{array}$ \\
\hline 2.9 & & 0.92 & .158 & $\begin{array}{l}+(\mathrm{dc}=.105) \\
-(\mathrm{dc}=.12 ; .135 ; .15)\end{array}$ \\
\hline 2.3 & & .12 & .206 & $\begin{array}{l}+(\mathrm{dc}=.135) \\
-(\mathrm{dc}=.15 ; .165 ; .18 ; \\
.195)\end{array}$ \\
\hline & 1 & .079 & $\begin{array}{l}.147 \\
+(\mathrm{dc}=.08) \\
-(\mathrm{dc}=.1 ; .12 ; .14)\end{array}$ \\
\hline
\end{tabular}
alliance does not do any research Table III

(see equation

D.1). The alliance's joint profits are the duopoly profits when marginal costs are c', which is identical to the joint profits of a merger if the merged firm would not commit any R\&D. The merger is less profitable than the alliance as its $R \& D$ increases the profits of the merged firm, but reduces the profits of firm 2 (its marginal costs are c', which the R\&D does not change due to the license policy of the merged firm, and the market price falls). Saying that the merger is less profitable than the alliance (if $\rho=1$ ) is thus tantamount to saying that $R \& D$ by the merged firm reduces the joint profits (which, as simulations show, does indeed happen).

Interval 4: $\mathrm{c}^{\prime}<\mathrm{c}^{\prime} \leq \mathrm{c}$.

The expression $\Pi_{\mathrm{m}}^{\mathrm{J}^{*}(2)}-\Pi_{\mathrm{a}}^{\mathrm{J}^{*}(2)}$ is too long to be reproduced here. Simulations did not reveal any instant where this expression is negative, so the results seems to be that the merger is more profitable than the alliance.

To sum up, the merger is 'usually' more profitable than the alliance, with exceptions for 
intermediate values of $c^{\prime}$, and low values of $\gamma$. 